\title{
The Kamikatsura event and the Matuyama-Brunhes reversal recorded in lavas from Tjörnes Peninsula, northern Iceland
}

\author{
P. Camps* \\ B. S. Singer ${ }^{\dagger}$ \\ C. Carvallo \\ A. Goguitchaichvili ${ }^{\S}$ \\ G. Fanjat \\ B. Allen
}

\begin{abstract}
We report paleomagnetic results from four overlapping stratigraphic sections (55 flows) through the lava pile in Tjörnes peninsula (North Iceland). The initial aim of our study was to check the existence of intermediate directions previously interpreted as belonging to the Matuyama-Brunhes geomagnetic reversal (MBR), and complete this record with ThellierThellier paleointensity determinations and ${ }^{40} \mathrm{Ar} /{ }^{39} \mathrm{Ar}$ radioisotopic dating. The directional results corroborate the findings by Kristjansson et al. [1]: a sequence of reversed, transitional, normal, and transitional polarity (R-T-N-T) is found in each section. The polarity change is characterized by a jump from reversed virtual geomagnetic poles (VGPs) to a quasi-cluster of transitional VGPs located over China, followed by a second jump to a cluster of normal polarity before moving again towards intermediate polarities. Reversely magnetized flows exhibit a magnetic mineralogy well suited for paleointensity determination. Of these 25 flows, 20 yielded paleointensity estimates of good quality. Unfortunately, the systematic presence of coarse multidomain (MD) titanomagnetite in the transitional and normal polarity flows hampered paleointensity estimates for these flows. The Virtual Dipole Moments (VDM) calculated for the reversed polarity flows vary from 4.9 to $7.0 \times 10^{22} \mathrm{Am}^{2}$ with an arithmetic mean value of $5.5 \pm 0.8 \times 10^{22} \mathrm{Am}^{2}$. This value is identical to the mean VDM obtained for the 0.3-5 Ma time window and thus strengthens the conclusion that the recent geomagnetic field strength is anomalously high compared to that older than $0.3 \mathrm{Ma} .{ }^{40} \mathrm{Ar} /{ }^{39} \mathrm{Ar}$ isochron ages were obtained with the incremental heating technique on groundmass separates or phenocryst-poor whole rock samples. Six of the transitionally magnetized lavas yielded isochron ages that are indistinguishable from one another at the $95 \%$ confidence level. The weighted average age is $862 \pm 51 \mathrm{ka}$. In the upper part of this volcanic sequence, the normally magnetized flows yielded a weighted average age of $787 \pm 40 \mathrm{ka}$. This finding supports the conclusion that a geomagnetic excursion within the Matuyama Chron is recorded in the lower part of the Tjörnes volcanic sequence, whereas only the latest portion of the MBR is recorded by flows in the upper part of the lava pile. This conclusion is supported via comparison of the VGPs obtained from the lavas with those predicted by a geomagnetic field model.
\end{abstract}

\section{Introduction}

The polarity reversal of the Earth's magnetic field is one of the most spectacular phenomena in the physics of the Earth. In only about 3 to $7 \mathrm{kyr}[2,3,4]$, the field changes from a dipolar configuration of a given direction to a similar configuration but of opposite direction.

The last decade has brought significant advances in the geodynamo modeling. Since the pioneering survey by Glatzmaier and Roberts [5], several numerical models of convection-driven

\footnotetext{
*Géosciences Montpellier, CNRS and Université de Montpellier 2, Place Eugène Bataillon, 34095 Montpellier, France.

$\dagger$ Department of Geoscience, University of Wisconsin-Madison, 1215 West Dayton St., Madison, WI 53706, USA.

${ }^{\ddagger}$ Institut de Minéralogie et Physique des Milieux Condensés, Université Pierre et Marie Curie, 4 place Jussieu, 75252 Paris, France.

$\S$ Laboratorio Interinstitucional de Magnetismo Natural, Instituto de Geofísica, Unidad Michoacán, Universidad Nacional Autónoma de México, Campus Morelia, Mexico.
} 
dynamo in spherical shells are able to provide a precise description of the evolution of the reversing field morphology which is not a priori forced by the model assumptions [see 6 , for a review]. It would obviously be necessary to compare these models with observations. Unfortunately, the paleomagnetic analyses have provided up to now only incomplete observations of the transitional field. Consequently, only the statistical characteristics of reversals have been compared with the dynamo simulation outcomes. Current comparisons between numerical models and observations focus either on the long-term time variations of dynamo properties [7] or on the reversal frequency $[8,9]$. Such comparisons will gain in significance when characteristics for an individual reversal will be more clearly defined [see also 10, for a detailed review].

There are three broad reasons for this basic scenario. First, and perhaps the prime reason is that ideally, it is necessary to have several recordings that document the same reversal at multiple sites significantly distant over the globe. Because a geomagnetic polarity reversal is a global phenomenon, it has to be observed at a global scale. Second, these recordings must be as continuous as possible to get insights on the temporal nature of the process within the transition. Third, as highlighted by Proctor [11], only a complete description of the vector field, both in terms of paleodirection and paleointensity, can be discriminating between several models. This last requirement forces to seek descriptions of the transitional field preferably from its recording by volcanic rocks, which constitute a faithful recorder and allow under some specific conditions to recover the absolute paleointensity. Nevertheless, volcanic recordings include several drawbacks. Because the volcanic activity is by nature discontinuous, no single sequence is able to capture a reversal in its entirety and the relative chronology from an area to another cannot be established directly. Much more restrictive are the uncertainties associated with the age estimates of rocks older than $\sim 5 \mathrm{Ma}$, which make it impossible to demonstrate that some recordings document the same reversal. Therefore, obtaining reliable time series of full vector of the geomagnetic field during an individual reversal appears as one of the most important and challenging problems in paleomagnetism.

In the last few years, the paleomagnetic community has worked to better document the last polarity reversal, i.e., the Matuyama-Brunhes Reversal (MBR). The prime reasons to focus on the MBR are certainly its young age and wealth of records to explore. Up to now, six paleomagnetic recordings suspected to span the MBR are derived from lava, namely: Punaruu Valley, Tahiti [12, 13]; Tatara-San Pedro, Chile [14, 15, 16]; Haleakala, Maui [17]; La Palma, Canary Islands $[18,19]$; Basse Terre, La Guadeloupe [20]; and Tjörnes Peninsula, Iceland [1]. In an attempt to better specify the age and duration of the MBR, Singer et al. [21] compared ${ }^{40} \mathrm{Ar} /{ }^{39} \mathrm{Ar}$ ages obtained by incremental heating of transitonally magnetized lava flows and showed that lavas in Chile, Tahiti and La Palma record a precursory geodynamo instability that preceded the actual MBR - known to be recorded only by lava flows on Maui - by about 18 kyrs. Hence, the change from reversed-to-normal stable polarity may have involved complex processes including weakening of the dipole field long before the actual polarity reversal took place.

Duration and degree of simultaneity of MBR remain uncertain. Clement [3] observed a site location dependence on the reversal duration from some sedimentary records of the four most recent polarity reversals, with shorter durations observed at low-latitude sites, and longer durations observed at mid- to high-latitude sites. The geomagnetic model proposed by Leonhardt and Fabian [22] for MBR also suggests large duration differences, emphasizing the rule of the non-dipole field during the transition. Age estimates for the actual MBR also vary, but a recent comparison of astrochronologic ages determined from marine sediment cores in which combined O-isotope and paleomagnetic records have been obtained gives an age of $773 \pm 1$ ka (Channell et al., 2010) which is in excellent agreement with the radioisotopic ${ }^{40} \mathrm{Ar} /{ }^{39} \mathrm{Ar}$ age of $776 \pm 2$ ka obtained from transitionally magnetized lava flows on Maui (Coe et al., 2004; Singer et al., 2005), provided the latter are calculated relative to a 28.02 Ma age for the Fish Canyon sanidine standard.

To further document the MBR in as great detail as possible, we undertook a comprehensive investigation of four volcanic stratigraphic sections in Tjörnes Peninsula (Iceland) thought to record this reversal [1]. In the first part of this paper, we report directional data that corroborate exactly the sequence of reversed, transitional, normal, and transitional polarity (R-T-N-T) as initially described by Kristjansson et al. [1]. Next, we demonstrate from a detailed rock magnetism investigation, that, within the current experimental techniques, paleointensity estimates can be recovered solely for the reversely magnetized flows. Finally, we present and discuss new ${ }^{40} \mathrm{Ar} /{ }^{39} \mathrm{Ar}$ ages that link these lava sections to the MBR. 


\section{Geological setting and paleomagnetic sampling}

The Tjörnes peninsula $\left(66^{\circ} 00^{\prime} \mathrm{N}-66^{\circ} 12^{\prime} \mathrm{N}, 16^{\circ} 57^{\prime} \mathrm{W}-17^{\circ} 24^{\prime} \mathrm{W}\right)$ is located at the eastern ending of the Tjörnes fracture zone, which is a set of transform faults featuring a ridge jump of $\sim 100 \mathrm{~km}$ between the rift zone in north Iceland to that of the southern Kolbeinsey Ridge (Figure 1). In this geodynamic context, the peninsula corresponds to a horst bounded to the east by the holocene Theistareykir fissure swarm in the active rift zone and to the south by the Húsavík-Flatey fault, a major fault where the main transform motion seems to be localized [23]. This area has a complex tectonic history characterized by a succession of subsidence and uplift periods associated with rifting and magmatism inside the rift zone.

A thick sequence $(\sim 1000 \mathrm{~m})$ of alternating terrestrial and fossiliferous marine sediments and interbedded lava flows of late Miocene and Plio-Pleistocene age is exposed on Tjörnes peninsula. Eiriksson [24] subdivided the entire Tjörnes sequence into four lithostratigraphical units (Figure 1): (i) the Kaldakvísl unit, of late Miocene age, corresponds mainly to a sequence of subaerial lava flows, (ii) the Tjörnes beds unit includes about $500 \mathrm{~m}$ of sediments of Pleistocene age with very few interbedded pillow lavas, (iii) the Höskuldsvík unit encompasses six thick lava flows assumed to be erupted during the Gauss and Matuyama epochs, and (iv) the Breiðavík unit, defined from the lowest tillite bed $(\sim 2 \mathrm{Ma})$ up to the present soil cover, is an over $600 \mathrm{~m}$ thick sequence of lava flows and sediments with evidence of 14 glaciations. The near-horizontal Breiðavík unit rests unconformably on the older formations that dip about $10^{\circ}$ toward the northwest. This unconformity is easily identified at a regional scale.

Comprehensive paleomagnetic studies have been carried out on Tjörnes beds [25] and Höskuldsvík and Breiðavík groups [26, 27]. Kristjansson et al. [1] described the Matuyama-Brunhes transition from a $200 \mathrm{~m}$ thick sequence of basalt lavas and hyaloclastites belonging to the upper part of the Breiðavík group. Their sampling was performed in the central part of Tjörnes along four overlapping cross sections at mount Grasafjöll (section GF), mount Búrfell (section BA) and mount Grísatungufjöll (sections GM and GS) (Figure 1). In the present study, we resampled these four sections almost exactly at the same place with however a different sampling strategy: we collected cores from each consecutive volcanic unit whereas Kristjansson et al. [1] sampled only one unit when a series of thin flows seemed to belong to the same eruption event. In order to be consistent with the former study, we kept the same name for lava flows and added a letter to distinguish flow units within Kristjansson et al. [1]'s groups. The sampling was carried out identically for each section. We collected an average of six cores from every consecutive flow with a gasoline-powered portable drill. The lateral extension of the sampling along a flow varies from several meters to more commonly, tens of meters. We oriented the samples with a magnetic compass corrected for local and regional anomalies by sighting either the sun at a known time or known landmarks. In total, 328 oriented cores belonging to 55 units were sampled. However, as icelandic lava flows can extend over a long distance, it is probable that some flows were sampled several times along different cross sections. Note that we were not able to take samples from flows GM3 and BA10 because they were covered with snow at the time of sampling.

In the laboratory, samples were cut into standard cylindrical paleomagnetic specimens, then they were stored in a null magnetic field during at least three weeks before being analyzed. We applied, as recommended by Kristjansson et al. [1], a very small tectonic tilt correction of $1^{\circ}$ toward the northeast.

\section{Paleodirection determinations}

\subsection{Experimental procedures}

Before magnetic cleaning, the 15-day magnetic viscosity index $\nu$ [28] was estimated for the whole collection by measuring the remanent magnetization first after a two-week storage with the ambient field parallel to the positive cylindrical axis of specimen $\left(\vec{M}_{1}\right)$ and then after another two-week 
storage in zero field $\left(\vec{M}_{2}\right)$. This index, expressed in percent by :

$$
\nu=\frac{\left|\vec{M}_{1}-\vec{M}_{2}\right|}{\left|\vec{M}_{2}\right|} \times 100
$$

can be used as a quantitative estimate of the Viscous Remanent Magnetization (VRM). Actually, Prevot [29] showed that the ratio of VRM acquired in situ since the beginning of the Brunhes epoch to the Characteristic Remanent Magnetization (ChRM) is estimated for subaerial lava to be 3-4 times as large as the viscosity index $\nu$. Tjörnes basalts are characterized by very low viscosity indices, all in the range $0-15 \%$. As commonly observed, a log-normal distribution, in the present case with a median value of $1.2 \%$ and a geometric mean of $0.7 \%$, fits perfectly the viscosity index distribution. We concluded that significant VRM overprints were unlikely and consequently, we used alternating fields (AF) cleaning to recover the paleodirections. As usually performed in our laboratory, we first treated one pilot sample from each flow using a detailed experimental procedure involving up to 18 AF cleaning steps. Then, we demagnetized the remaining samples with a reduced number of selected steps, assuming that the remanence properties are homogeneous at flow scale. The majority of samples from sections GS and BA have been treated with a laboratory built AF demagnetizer providing AF peak values up to $140 \mathrm{mT}$, the remaining remanence was measured after each cleaning step with a JR-5A spinner magnetometer. The few remaining samples and all samples from GF and GM sections were demagnetized and measured with a three-axes 2G cryogenic SQUID magnetometer equipped with the 2G600 AF demagnetizer.

\subsection{Results}

The analysis of the demagnetization diagrams is straightforward for all the samples. A small low-coercivity overprint, of certainly viscous origin, is observed in most flows. This overprint is entirely destroyed between 10 and $30 \mathrm{mT}$. For higher AF peak values, we observed a perfect stability of the primary magnetization direction as shown by the straight-line decay to the origin on the vector endpoint diagrams (Figure 2). We determined the ChRM by means of principal component analysis, averaged the directions thus obtained by flow, and calculated the statistical parameters assuming a Fisherian distribution. The average directions for all lava flows are listed in supplementary Table S1 and their variation through each volcanic sequence is illustrated on supplementary Figure S1 by means of equal-area azimuthal projections. These results corroborate exactly the findings by Kristjansson et al. [1]: a R-T-N-T polarity sequence is found in each section with a remarkable consistency in the transitional directions from one section to another.

The stratigraphic relationships of the lava flows on Tjörnes Peninsula are well established from geological evidence and paleomagnetic data [27], respectively. It is noteworthy that the paleomagnetic directions obtained in the present study can perfectly be combined into a composite profile consistent with the geological markers such as glacial horizons and erosional contacts [27]. In order to gain in clarity, this was done and synthetic results are summarized in supplementary Table S2.

Two points regarding the paleodirection determinations need a comment. The first point concerns the large values for the confidence angles $\alpha_{95}$ about the mean directions obtained for flows GS3, GS4, and GS5. The outcrop on this part of the section is of poor quality due to the weak slope of the hill. We noted during the field work that some blocks we drilled could be tilted by an unknown amount. That is certainly the cause for the large within-flow remanence scatter in these three flows. These flows would normally be omitted from further consideration. However, we believe reliable their mean directions because they are in close agreement with the directional results obtained from coeval flows from sections BA, GM, and GF. Thus, we decided to include these recordings in the directional group analysis (supplementary Table S2). For all the other flows, the ChRM are well clustered by flow, nearly all having $\alpha_{95}$ less than $10^{\circ}$. The second point concerns the relevance of Kristjansson et al. [1]'s field observations to consider that several successive flows belong to the same eruption event. Our paleomagnetic results confirm that each eruption phase identified by Kristjansson et al. [1] corresponds to a set of lava of which $\alpha_{95}$ confidence angles for the mean directions overlap. 


\section{Magnetic properties of samples}

\subsection{Objectives and experimental procedures}

Paleointensity determinations from volcanic rocks by means of the Thellier and Thellier [30]'s method are frequently characterized by a high failure rate, commonly of the order of 70 to $90 \%$. Failure is mainly caused either by alteration of the magnetic minerals and consequently of their magnetic properties during laboratory heatings or by the unwanted presence of multi-domain grains in the rocks since they display a non-ideal magnetic behavior in Thellier experiments. A good knowledge of the nature, the size and the thermal stability of the thermoremanence carriers present in the rock is thus essential prior to any attempt to estimate the paleointensity. For this purpose, we carried out several experiments:

1. Low-field susceptibility versus temperature curves (KT curves); These measures allow to account for the stability of the Fe-Ti oxides upon heatings and allow to determine their Curie temperature. They were performed at low- and high-temperatures with the cryostat apparatus CS-L and the furnace CS-3 under Argon atmosphere coupled to the KLY-3 Kappabridge instrument (Agico, Czech Republic). For this experiment, bulk rock samples have been grounded in an agate mortar and sieved by means of fine nylon meshes to obtain 0.1-0.8 $\mathrm{mm}$ size fractions. At least one sample per flow was heated first from the liquid nitrogen temperature $(78 \mathrm{~K})$ to $900 \mathrm{~K}$ and cooled down to room temperature. Then, the low-temperature measurements were repeated by heating again from $78 \mathrm{~K}$ up to room temperature. The raw susceptibility data were corrected for the empty sample holder and normalized to the maximum susceptibility.

2. First-order reversal curve (FORC) diagrams; These diagrams allow a qualitative characterization of the magnetic domain structure even for materials containing a mixed grain-size assemblage [31]. They were performed at room temperature on few selected samples with the Micro Vibrating Sample Magnetometer of the CEREGE Institute (Aix en Provence, France). Numerical processing was carried out with the FORCanalysis software provided by Pike [31].

3. Optical ore microscopy; To aid in the interpretation of KT curves and FORC diagrams, microscopic observations in reflected light were performed on polished thin sections prepared from specimens cut in the cylinder cores. We used a Leitz orthoplan microscope which allows a maximum magnification under oil-immersion of 1250X. Fe-Ti oxide assemblages and textures were determined following the Haggerty [32]'s classification.

4. Electron Probe MicroAnalysis (EPMA); We performed quantitative chemical analyses of individual magnetic mineral with a CAMECA SX100 microprobe. Hereby, Curie temperatures given by the KT curves can be directly compared with the expected one calculated from the titanomagnetite chemical composition. Calculations of the ulvöspinel molecular fraction $x$ in the titanomagnetite structure were made following the procedure described by Prevot et al. [33]. We calculated the number of atoms $\delta$ within the titanomagnetite structure in a stoichiometry of three cations for four $\mathrm{O}^{2-}$, assuming that minor elements ( $\mathrm{Al}$ and $\mathrm{Mg}$ ) are substituted for Fe. Thus, in this model $x$ is directly given by the number of atoms of titanium $\delta_{T i}$.

\subsection{Results}

We distinguished three types of Fe-Ti oxides-bearing samples according to the characteristics of the KT curves.

\subsubsection{Type H samples}

Type H samples represent roughly $30 \%$ of the whole collection. They are characterized by a single magnetic phase with high mean Curie temperature between 830 and $853 \mathrm{~K}$, a feature that indicates a pure or nearly pure magnetite composition (Figure 3a). The sharp decrease of the susceptibility at the Curie temperature denotes a rather homogeneous chemical composition at the sample scale. 
All samples of this type present a peak in susceptibility at low-temperature, between 100 and 120 K. Similar behavior in KT curves is commonly observed in subaerial lava [34, 35, 36] and are generally associated to the presence of Ti-poor titanomagnetite subdivided by trellis lamellae of ilmenite formed during deuteric oxidation. Thin section analyses of type $\mathrm{H}$ samples have confirmed the presence of such simple two-phase assemblage corresponding to oxidation stage C3 of Haggerty [32] (Figure 4a), but also have yielded evidences for more advanced stages of oxidation within the same sample, i.e., at the thin section scale. In some grains, rutile lenses develop in the exsolved ilmenite and spinel rods in the titanomagnetite host (stage C4) while the presence of hematite and pseudobrookite in some other grains characterizes higher degrees of oxidation (stages C5 and C6). It is noteworthy that we observed the same range in the degree of oxidation for the primary ilmenite laths (from stage R3 to stage R6). The tiny size of the texture and the heterogeneous degrees of oxidation, from $\mathrm{C} 3(\mathrm{R} 3)$ through $\mathrm{C} 6(\mathrm{R} 6)$, preclude for this group a precise identification of the Fe-Ti oxide assemblage by means of microprobe chemical analysis.

According to the experimental work of Senanayake et al. [37], the low-temperature peak observed in KT curves is an evidence for a predominance of multidomain (MD) pure or nearly pure magnetite. This conclusion is at variance with the FORC diagrams that rather indicate that the magnetic grains are mainly in a weak interacting single domain (SD) state (Figure 5a). At present, we do not have a clear explanation to give an account of this discrepancy. From our microscopic observations, we believe that type $\mathrm{H}$ samples correlate to a mixture of a prevailing fraction of SD grains and a trifling fraction of MD grains. Hence we have to assume that the MD grain fraction is small enough to have no significant contribution to the remanent magnetization and thus this population would not be detected by the FORC measurements but would have a sufficient contribution to the induced magnetization to be detected by low-temperature susceptibility curves.

\subsubsection{Type L samples}

About $10 \%$ of samples belong to this second group. Type L samples show a single magnetic phase with a low mean Curie temperature in the range 300-380 K (Figure 3c). As for type H samples, the sharp decrease at the Curie temperature indicates that the Fe-Ti oxides have a homogeneous chemical composition at the sample scale. KT curves are outlined at low temperature by a strong increase in susceptibility with increasing temperature until the Curie temperature is reached. Clearly, our type L samples correspond to Senanayake et al. [37] and Kontny et al. [36]'s group 1 samples which are indicative of homogeneous rich-Ti titanomagnetites that are predominantly MD at room temperature. Optical microscopy observations reveal the presence of large titanomagnetite grains $(100-150 \mu \mathrm{m})$ that are optically homogeneous up to very large magnifications (stage C1). Some grains can present very few exsolved ilmenite lamellae (stage C2) as illustrated on Figure 4c. The MD structure of these large quasi-homogeneous grains is indisputable. This magnetic domain state is double-checked with FORC measurements which produce characteristic MD contours that all diverge away from the origin (Figure 5c). Electron microprobe analysis has been carried out for one thin polished section (97T080). As expected, measures performed on 16 different Fe-Ti oxide grains indicate an overall homogeneous titanomagnetite composition with a mean ulvöspinel molecular fraction of $x=\delta_{T i}=0.69 \pm 0.02$ with $\delta_{A l}=0.068 \pm 0.007$ and $\delta_{M g}=0.068 \pm 0.009$. The corresponding Curie temperature is $352 \pm 18 \mathrm{~K}$ according to the experimental data obtained on synthetic minerals [38]. This value is lowered to $308 \pm 18 \mathrm{~K}$ when the correction for $\mathrm{Al}$ and $\mathrm{Mg}$ substitutions is applied [39], which is very close to the $\sim 300 \mathrm{~K}$ directly measured from the whole rock in the KT curve. This good agreement denotes the absence of low-temperature oxidation.

\subsubsection{Type LH samples}

This third group is represented by about $21 \%$ of samples. Type LH samples correspond in every points to a mixture between the two type $\mathrm{L}$ and $\mathrm{H}$ populations such as described above. On KT curves, one observes at once the peak in susceptibility at low-temperature around 100-120 K associated with a high curie temperature $(>830 \mathrm{~K})$ as well as the phase with low Curie temperature $(300-380 \mathrm{~K})$ which comes with a strong increase in susceptibility from $\sim 150 \mathrm{~K}$ up to room temperature (Figure 3b). FORC diagrams show also a clear contribution of two populations being for the first SD-like with closed inner contours and for the second MD-like with diverging outer 
contours (Figure 5b). These interpretations are strengthened by optical microscopy analyses that revealed the presence of titanomagnetite with various degrees of oxidation encompassing the ranges observed in type L samples (C1-C2) and H samples (C3-C6). Twin titanomagnetite crystals, striking by their size and shape, located in a very near vicinity can present different textures and oxidation stages (Figure 4b). It should be emphasized that this unusual observation is equally repeated for primary ilmenite laths. We performed micropobe analysis on nine selected crystals (sample 97T168) assumed to be representative of type L fraction. These crystals show large area of optically homogeneous titanomagnetite, and thus are likely to be affected only by an early stage of oxidation. This population is characterized by a mean ulvöspinel molecular fraction of $x=\delta_{T i}=0.66 \pm 0.04$, with $\delta_{A l}=0.071 \pm 0.006$ and $\delta_{M g}=0.052 \pm 0.006$. The expected Curie temperature, calculated with the experimental data of Lattard et al. [38] and corrected for $\mathrm{Al}$ and $\mathrm{Mg}$ substitution [39], is $336 \pm 37 \mathrm{~K}$. This value is in a reasonable agreement with the observed mean value of $350 \pm 50 \mathrm{~K}$ for the low Curie temperature phase present in this sample (Figure $3 \mathrm{~b}$ ).

\subsubsection{Irreversible KT samples}

A large part of the collection, about $39 \%$ of samples, includes samples clearly belonging to one of the three groups as defined above but presenting a nonreversibility in their KT curve. Oxidation during the laboratory heatings is questionable since these later are performed under Ar-atmosphere in order to reduce mineral reactions with oxygen. However, oxidation can not be totally rule out since oxygen is necessary present in rocks, and its fugacity is increased with increasing temperature [40]. An alternative interpretation is to consider a cation-deficiency, present before the laboratory heatings and of unknown origin, as the cause of irreversibility assuming that heating to $900 \mathrm{~K}$ allows some Ti to diffuse into the magnetite lattice, producing a slightly more Ti-rich spinel phase in the cooling curve. No further investigations have been performed on these samples since they are in all cases ill-suited for paleointensity determinations.

\section{Paleointensity determinations}

\subsection{Sample selection}

Volcanic rocks used for absolute paleointensity determinations must satisfy the following conditions :

1. The ChRM must be a Thermo-Remanent Magnetization (TRM) not disturbed by a significant secondary component.

2. The magnetic properties of the samples must be reasonably stable during experimental heating in the laboratory.

3. The remanence carriers must be Single Domain (SD) or Pseudo-Single domain (PSD) grains in order to fulfill the independence and additivity laws of partial Thermo-Remanent Magnetization (pTRM) [30].

On the basis of the presence of an exclusive or a large fraction of MD grains in samples of type $\mathrm{L}$ and LH, respectively, only samples of type $\mathrm{H}$ appear suitable for paleointensity determinations. This observation is a very important restriction in the present study since type $\mathrm{H}$ samples are almost exclusively present in the lower parts of sections, i.e., in flows of reversed polarity. We identified only one sample of type $\mathrm{H}$ in a normal polarity flow (GS10) and none in intermediate polarity flows. In addition, to fulfill condition 2, we kept only the samples for which the KT curve is reasonably reversible, and to fulfill condition 1, those having a viscosity index lower than $5 \%$ and no significant secondary component in their remanence according to AF treatments. After screening, 103 samples of type $\mathrm{H}$ were selected. We also analyzed three samples of type LH with reversible KT curves just to check, as suspected, that they are non-ideal paleointensity recorders. 


\subsection{Experimental procedures}

Paleointensity determinations were carried out in the Montpellier laboratory with the Thellier and Thellier [30] method in its classical form. The samples are heated and cooled twice at each temperature step $T_{i}$ in presence during the cooling of a 50- $\mu \mathrm{T}$ induction field oriented along the $\mathrm{z}$-axis of the specimens for the first cycle and in the opposite direction for the second one. Eleven temperature steps up to $545^{\circ} \mathrm{C}$ were accomplished for each sample with decreasing increments as the temperature increases $\left(150,40,30,20\right.$ and finally $\left.15^{\circ} \mathrm{C}\right)$. In order to detect alteration of the TRM spectrum as the laboratory heating temperature is progressively increased, this double-heating protocol is accompanied with a sliding pTRM check procedure [41]. The principle is to reinvestigate the pTRM capacity in a given temperature interval after heating to higher temperature. Here we remeasured, throughout the whole experiment, the pTRM intensity acquired in a temperature interval from $T_{i-2}$ to $T_{\text {room }}$ after heating at $T_{i}$.

The remanence was measured subsequent to each heating-cooling cycle at room temperature with a JR-5A spinner magnetometer. All heating-cooling cycles were performed under a vacuum better than $10^{-2} \mathrm{~Pa}$ in order to limit possible oxidation during experiment. Each heating-cooling cycle required between seven and ten hours. This long-lasting procedure is due to the vacuum. Temperature reproducibility between heatings at the same step is within $1^{\circ} \mathrm{C}$. This control is ensured by means of three thermocouples placed at different positions within the heating chamber, plus three others sealed inside three dummy samples. The intensity of laboratory field has a precision better than $0.1 \mu \mathrm{T}$. We would like to point out that we do not have any data beyond $545^{\circ} \mathrm{C}$ because our paleointensity oven encountered a serious technical problem during the first run at $560^{\circ} \mathrm{C}$. More than the very long time required for repair, a harmful consequence was that the small fraction of the remaining NRM of samples which were being heated was removed and replaced by a total TRM acquired under a very strong uncontrolled magnetic field.

\subsection{Analysis of paleointensity data}

The representation and statistical analysis of paleointensity data were carried out with the ThellierTool software provided by Leonhardt [42]. In this software, the basic statistical parameters are those introduced by Coe et al. [43] with the modifications proposed by Prevot et al. [41].

We adopted a standard set of strict criteria derived from those of Selkin and Tauxe [44] and Plenier et al. [45] to interpret the individual paleointensity data and screen out those of poor technical quality. They are essentially based on three types of considerations from:

1. NRM-TRM diagrams: Paleointensity measurements were represented and analyzed by means of Arai diagram in which the NRM remaining is plotted against the TRM acquired after each pair of heating experiment. The slope of the least-squares-fit line computed from the linear part of these plots gives an estimate of the paleointensity. A paleointensity value is rejected when the least squares segment is defined by less than four points $(n<4)$ or span no more than $30 \%$ of the total NRM $(f<0.3)$.

2. pTRM checks : It is now widely accepted that a linear part on NRM-TRM diagram is not a proof by itself of the absence of alteration in TRM spectrum during Thellier experiment [e.g. 35]. Hence pTRM checks must be performed to assess the reliability of a paleointensity estimate. We quantified the difference between two pTRM acquisitions at the same temperature by means of the Difference Ratio (DRAT) parameter [44]. DRAT is expressed in percent and corresponds to the maximum difference measured between repeated pTRM acquisition normalized by the length of the selected NRM-TRM segment. A maximum acceptable threshold is fixed arbitrarily at $10 \%$.

3. Vector endpoint diagrams : Jointly, we checked on the directional plots computed from the paleointensity experiments that the NRM fraction used to calculate the paleointensity corresponds effectively to the ChRM of the core. For instance, the low-temperature part of the NRM may contain natural secondary magnetizations, and a spurious remanent magnetization acquired during the laboratory Heating (HRM) may superpose to the NRM if chemical changes in the magnetic minerals occurred. First, this check is achieved qualitatively by a visual inspection of the vector endpoint diagrams. The points in the selected interval should 
trend toward the origin if the NRM is the ChRM. Actually, the acquisition of HRM must show in core coordinates a progressive deviation of the demagnetization curve in the vertical plane towards the vertical axis direction since the laboratory field is applied along the core z-axis. Next a quantitative estimate of the HRM is allowed if we know the exact ChRM direction. This is achieved by calculating the $z$ parameter $[46,47]$ at each heating steps $T_{i}$ :

$$
z\left(T_{i}\right)=\frac{\left|\mathbf{H R M}_{T i}\right|}{\left|\mathbf{N R M}_{T i} / / \mathbf{C h R M}\right|} \times 100
$$

where $\mathrm{NRM}_{T_{i}} / / \mathrm{ChRM}$ is the NRM left along the ChRM direction after heating at $T_{i}$ assuming that the ChRM direction be known from the demagnetization of a sister specimen from the same core. From geometrical considerations, it can be easily demonstrated that $z$ is equal to:

$$
z\left(T_{i}\right)=\frac{\sin (\alpha)}{\sin (\theta-\alpha)} \times 100 \quad \text { if } \quad \alpha \neq \theta
$$

where $0<\alpha<180^{\circ}$ is the angle between the NRM and the ChRM, and $0<\theta<180^{\circ}$ is the angle between the ChRM and the applied field direction. A threshold of $20 \%$ was arbitrarily chosen for $z$. Of course, spurious HRM is more easily detected, visually or quantitatively, when the applied field direction is perpendicular to the ChRM, e.g., $\theta=90^{\circ}$. Unfortunately, the tray we used in the oven to hold the specimens does not allow to choose the orientation of the ChRM with regard to the applied field.

\subsection{Paleointensity results}

In total, 88 out of the 103 preselected samples of type $\mathrm{H}$ yielded an acceptable paleointensity estimate, within the set of quality criteria as mentioned above. The selected values for individual specimens are listed in supplementary Table S3 and a qualitative appreciation of the results is given for two flows on supplementary Figure S2. The overall analytical quality of these determinations is very good. Well-defined straight segments on NRM-TRM curves are generally observed over a large range of NRM fraction; $75 \%$ of paleointensity estimate are calculated with a NRM fraction greater than 50\%. Another indicator concerning the good analytical precision is given by the quality factor q which ranges in the present study from 6 to 57. Obviously, this parameter would have been even larger for some samples if we had been able to heat beyond $545^{\circ} \mathrm{C}$.

We calculated for each flow a weighted mean paleointensity with the weighting factors of Prevot et al. [41] and estimated the uncertainty of the mean with equation (5) of Coe et al. [43]. The individual paleointensity estimates are fairly coherent when they are compared within a single lava flow as attested by the small within flow standard errors, all being less than $8 \%$ of the average (supplementary Table S3). However, the flow-average paleointensities display a large between-flow scatter, ranging from $26.9 \pm 2.3 \mu \mathrm{T}$ to a maximum of $48.9 \pm 3.2 \mu \mathrm{T}$.

Among the 15 samples not selected, 10 are rejected in spite of a good linearity in NRM-TRM points (supplementary Figure S3a) because a too small NRM fraction is destroyed $(f \leq 0.3)$ before irreversible magneto-chemical changes arise $($ Drat $>10 \%)$, and five are rejected because of curved Arai plot (supplementary Figure S3b). The irreversibility of the magnetic properties is generally observed after heating at a temperature around $500^{\circ} \mathrm{C}$. It is noteworthy that none of these 15 rejected-samples exhibit a significant deviation of the NRM direction toward the applied-field direction caused by the acquisition of a spurious HRM. We did not select samples of type LH since they contain a large fraction of MD grains. The only three samples measured nevertheless show, as expected, a non-ideal behavior in paleointensity experiment as featured by concave-up NRMTRM curves (supplementary Figure S3c). These observations validate a posteriori our sample preselection.

\section{$6 \quad{ }^{40} \mathrm{Ar} /{ }^{39} \mathrm{Ar}$ Age determinations}

\subsection{Analytical Procedure}

Samples were prepared in two ways. The first involved taking a 5-mm-diameter core drilled out of the 2.5-cm-diameter paleomagnetic core to make whole-rock wafers. Samples are prepared as a 
wafer when phenocryst phases are absent to avoid any contamination by Ar from mantle origin. These cores were then sawed to make each piece approximately $150 \mathrm{mg}$. Three to four wafers of each sample were selected for the irradiation. The second method is used to eliminate potential contamination from xenocrystic phases, principally olivine. The samples were crushed with an iron mortar and pestle, sieved and separated into different size fractions. Then, the samples were washed ultrasonically in acetone and de-ionized water bath to eliminate dust. The 250-500 $\mu \mathrm{m}$ fraction was chosen because it was the largest fraction where the phenocryst phases in the material could be separated from the groundmass. A weak hand magnet was then used to remove any iron shavings incorporated into the sample from the mortar and pestle. To separate the iron oxide-rich groundmass from the phenocrysts, a stronger magnet was passed over the sample. A clean groundmass separate was obtained by handpicking out unwanted grains under a plain light binocular microscope. Whole rock wafers were loaded without being wrapped. Groundmass separates were weighted to $\sim 100 \mathrm{mg}$ and wrapped in copper foil. The samples were loaded into 2.5-cm-diameter aluminum discs along with crystals of the $1.194 \pm 0.012 \mathrm{Ma}$ Alder Creek rhyolite sanidine (ACs) that were used to monitor neutron fluence [48]. This age for the ACs standard is based on intercalibration to the primary standard GA-1550 biotite, which in turn is consistent with an age of $28.02 \pm 0.016 \mathrm{Ma}$ for the widely used Fish Canyon sanidine (FCs) [48]. For reasons discussed at length in Channell et al. [4], we prefer to report ${ }^{40} \mathrm{Ar} /{ }^{39} \mathrm{Ar}$ ages relative to $28.02 \mathrm{Ma}$ FCs, rather than the astrochronologically-constrained age of 28.201 Ma for this standard proposed by Kuiper [49]. The samples were irradiated at the Cadmium-Lined In-Core Irradiation Tube (CLICIT) at the Oregon State University Triga reactor where they received a fast-neutron dose of $1.8 \times 10^{15}$ neutrons $/ \mathrm{cm}^{2}$. Corrections for undesirable nucleogenic reactions on ${ }^{40} \mathrm{~K}$ and ${ }^{40} \mathrm{Ca}$ are as follow: $\left[{ }^{40} \mathrm{Ar} /{ }^{39} \mathrm{Ar}\right]_{\mathrm{K}}=0.00086 ;\left[{ }^{36} \mathrm{Ar} /{ }^{37} \mathrm{Ar}\right]_{\mathrm{Ca}}=0.000264 ;\left[{ }^{39} \mathrm{Ar} /{ }^{37} \mathrm{Ar}\right]_{\mathrm{Ca}}=0.000673[50]$.

At the University of Wisconsin-Madison Rare Gas Geochronology Laboratory, the samples were first degassed at temperatures between $440^{\circ} \mathrm{C}$ and $500^{\circ} \mathrm{C}$ to remove undesirable quantities of atmospheric argon and then incrementally heated for 11 to 15 steps between $500^{\circ} \mathrm{C}$ and $1220^{\circ} \mathrm{C}$ by means of a double vacuum resistance furnace. These temperatures were sustained for 15 minutes. The gas released to two SAES C50 Zr-Al Getters connected to the extraction line for seven minutes. The gas released from each heating step was then expanded into a Mass Analyzer Products 21550 mass spectrometer. The instrument was operated at a sensitivity of $1.4 \times 10^{-14} \mathrm{~mol} / \mathrm{V}$. We monitored the mass discrimination throughout the experiment with several dozen measurements of an automated air pipette, and found a value of $1.0067 \pm .0004(1 \sigma)$ per atomic mass unit during the analytical period. Uncertainty estimate for the neutron fluence parameter $\mathrm{J}$ is between $0.7 \%$ and $1 \%(1 \sigma)$. This uncertainty was carried through to the final age calculations for each sample, but contributes less than $0.1 \%$ of the total age uncertainty. Ages are calculated with the ArArCalc software of Koppers [51] and reported with $\pm 2 \sigma$ analytical uncertainties. Samples yield meaningful ages if: (1) an age plateau is defined from at least four successive steps all concordant at the $95 \%$ confidence level that comprise more than $50 \%$ of the total amount of ${ }^{39} \mathrm{Ar}$ released, and (2) a well-defined isochron exists for the plateau points as defined by the F-variate statistic SUMS/(N -2) [52]. The isochron ages are preferred over the weighted mean plateau ages because they do not require the assumption that the trapped argon component is atmospheric in composition [e.g., 17]. When multiple subsamples from a lava were measured, each was treated as independent from one another. The inverse-variance weighted mean of the isochrons combines to give the best estimate of the age and uncertainty for these flows $[17,50]$.

\subsection{Results}

The results of 25 incremental heating experiments on 12 Tjörnes lavas are summarized in supplementary Table S4 with complete analyses of each sample given in supplementary Table S5. All lavas but one (BA-3) yielded concordant or moderately concordant age spectra. Plateau segments contain 61.3 to $100 \%$ of the total ${ }^{39} \mathrm{Ar}$ released. Of these, only two (samples GS-5 and GS-2) were below $75 \%$; both were whole rock wafers. Concordant plateau ages from the lavas, including duplicate analyses, give ages of between $917 \pm 150$ and $1182 \pm 150$ ka for the reversely magnetized lavas at the base of the sections, $751.2 \pm 56.0$ and $931 \pm 48$ ka for transitionally magnetized lavas, and $845 \pm 57$ and $852.6 \pm 39.6$ ka for the normally magnetized lavas. Only sample from flow BA-3 displayed a discordant age spectra for two different heating experiments. Since the sample 
is strongly discordant, these results are not used in calculations of the mean age. The discordancy could be the result of ${ }^{39} \mathrm{Ar}$ recoil, alteration, or xenocrystic inclusions. Both experiments were conducted on whole rock, and not groundmass, leaving the potential for inherited Ar from phenocrysts phases such as olivine. The isochrons from these experiments give preferred ages between $926 \pm 400$ and $969 \pm 590$ ka for the reversely magnetized lavas, $691 \pm 142$ and $925 \pm 160$ ka for the transitionally magnetized lavas, and $768 \pm 53$ and $838 \pm 140$ ka for the normally magnetized lavas (supplementary Table S4). Uncertainties are typically $20-40 \%$ due to limited spread of data along the isochrons. The isochron ages give the preferred ages for these lava flows [50]. The 11 ages determined from the low-K tholeiitic lavas of the Tjörnes peninsula all agree with their stratigraphic positions, in part because the analytical uncertainties associated with an individual lava site are large. The weighted average isochron of the two reversely magnetized olivine tholeiite lavas, one at the base of each section, is $940 \pm 320 \mathrm{ka}$ (Mean Square Weighted Deviate $($ MSWD) $=0.2$ ), which at face value places them within the uppermost period of the Matuyama reversed Chron. Similarly, the weighted average age of the six transitionally magnetized lavas is $862 \pm 51 \mathrm{ka}(\mathrm{MSWD}=3.0$ ) and this is considered to be the best estimate of the time at which a geomagnetic field event took place. The weighted average of the three normally magnetized lavas in the GS section is $787 \pm$ $40 \mathrm{ka}(\mathrm{MSWD}=0.71$ ), which is consistent at the $95 \%$ confidence level with eruption during the MBR at $776 \mathrm{ka}$, the MBR precursor at $794 \mathrm{ka}$, or during the lowermost portion of the Brunhes Chron. Recalling that MSWD is simply a Chi-squared statistic to determine whether the isochrons represent a single population of ages, or multiple events [see i.e. 53], we point out that none of the MSWD values are large enough to suggest that averaging the isochron ages together is mixing more than one dated event.

\section{Discussion}

Our experimental data clearly distinguish the geomagnetic sequence recorded in the Tjörnes lava pile allowing precise stratigraphic correlations as illustrated in Figure 6. We believe that the aberrant magnetic field directions recorded in the lower part of the volcanic sequence, from DG4 to DG8 can not be associated with the Matuyama-Brunhes reversal itself. This can be argued on two points. The first is direct evidence from ${ }^{40} \mathrm{Ar} /{ }^{39} \mathrm{Ar}$ dating. The finding here is that, at the $95 \%$ confidence level, they occurred prior to the MBR by $82 \pm 51 \mathrm{ka}$. This difference is clearly illustrated on Figure 7 where ${ }^{40} \mathrm{Ar} /{ }^{39} \mathrm{Ar}$ ages - obtained with exactly the same analytical technique and relative to a common standard age - are represented together on the geomagnetic instability time scale (GITS) [19, 53] for the interval 500-1200 ka. The second is a more indirect evidence arising from a comparison of the experimental VGPs obtained in the present study to those predicted by the geomagnetic model IMMAB4 [22]. Tjörnes VGPs calculated from DG4-8 are not located along the reversal path predicted by the model (Figure 8). We grant a great credibility to this observation because this model was very efficient to simulate almost all the MBR paleomagnetic records, including those not used in its development. Thus, the lower Tjörnes lavas from DG4 to DG8 likely record a geomagnetic event during the late Matuyama chron. Two possibilities with respect to correlative events include the Kamikatsura and the Takatsuki event, respectively. The Kamikatsura event has now sufficient support from both sedimentary and volcanic records from several places worldwide to be considered as a well-established stratigraphic marker in the late Matuyama Chron [see 54, 13, 53, for reviews]. Its age was recently revised at 900.4 $\pm 4.6 \mathrm{ka}$ [17] from ${ }^{40} \mathrm{Ar} /{ }^{39} \mathrm{Ar}$ dating on transitionally magnetized lava from the Panauru Valley, Tahiti, and Haleakala caldera, Maui (Figure 7). Thus, the Kamikatsura event is well within the uncertainty of the age determined for the Tjörnes transitionally magnetized lavas. The Takatsuki event is less documented and thus still uncertain. To our knowledge, only one record was found in sediments exposed near Osaka, Japan [55]. These authors indicate two excursions closely spaced in time of about $20 \mathrm{ka}$. By means of K-Ar dating of volcanic tuffs, they have assigned an K-Ar age of $850 \pm 30$ ka for the upper one, that they tentatively call Takatsuki, and correlated the lower one to the Kamikatsura event. Because the Takasuki event is identified up to now at only one site, its global occurrence can be questioned. Actually, the record in Osaka sediments may only reflect a strong regional secular variation feature. Conversely, this remark can also apply to the Tjörnes excursion. However it is important to keep in mind that if two global events coming very close together really 
occurred during the late Matuyama chron as speculated by Takatsugi et al. [55], the possibility that Tjörnes excursion is correlative with the Takatsuki event should not be ruled out.

The normally magnetized flows, from DG9 to DG15, yielded a weighted average age of $787 \pm$ $40 \mathrm{ka}$. Given the uncertainty, two alternative correlations with the GITS might account for this result. The first is to correlate with the lowermost portion of the stable Brunhes Chron, while the second, which is our preferred interpretation, is to correlate with the last stage of the MBR (Figure 7). Here again, the most convincing suggestion comes from the IMMAB4 geomagnetic model. The VGPs calculated from DG9-15 match perfectly the reversal path as predicted by the model (Figure 8). Even more remarkable, however, is the similitude in the VGP locations between the ones calculated from the direction of the transitionally magnetized flows found at the top of each section, DG16 and DG17, and the ones computed from the IMMAB4 model for Tjörnes location, when the latter makes a N-T-N loop before achieving the full polarity reversal (Figure 8). We therefore suggest that only the last stage of the MBR has been recorded in the upper part of the Tjörnes volcanic sequence, from DG9 to DG17. In a very speculative way, we can use the model outcome to determine the age of these lava flows. Hence, if our hypothesis is correct, lava suspected to have recorded the end of MBR were erupted between model years 772.5 and $771.9 \mathrm{ka}$, a period during which the modeled paleointensities remain low (supplementary Figure S4). Unfortunately, the magnetic mineralogy encountered in these lavas did not allow us to obtain experimental values; only the reversely magnetized flows erupted during the Matuyama period and one sample from a "normally" magnetized flow belonging to DG14 yielded paleointensity estimates. We note that this later yield a paleointensity much higher than the calculated ones from the model (supplementary Figure S4). It would be very speculative to discuss further this point, this paleointensity being determined from a single sample.

A final point concerns the paleointensity determinations. In the present survey, $27 \%$ of samples yielded a reliable estimate, which is a typical success rate for subaerial lava flows. The Thellier and Thellier technique involves a stringent selection criteria to yield a paleointensity estimate. Among the 225 samples not selected for paleointensity experiments, 78 were excluded because we suspected the presence of an exclusive or a large fraction of MD grains, such domain size precluding any attempt in absolute paleointensity determination with the conventional Thellier and Thellier [30] method. Consequently, we emphasize the need to develop new paleointensity methods supported by theoretical considerations which will be independent of the magnetic domain size, such as those tentatively proposed by Dekkers and Bonhel [56], Poidras et al. [57], Fabian and Leonhardt[58], or Muxworthy [59].

\section{Conclusions}

Our comprehensive paleomagnetic and geochronologic study of the volcanic sequence from the upper part of the Breiðavík group in Tjörnes peninsula, North Iceland, leads to the following conclusions:

1. Stratigraphic correlations between the four overlapping profiles studied in the present survey are now well-established (Figure 6). They rely not only on the direction of the remanent magnetization but also on rock magnetism properties, ${ }^{40} \mathrm{Ar} /{ }^{39} \mathrm{Ar}$ isochron ages, and field observations. These correlations allow us to present the results in a composite profile (supplementary Table S2).

2. The directional results corroborate the finding by Kristjansson et al. [1] : a sequence of R-T-N-T polarity is observed. Our interpretation to correlate this polarity sequence to the geomagnetic time scale is however different than the one proposed in the former studies. Using ${ }^{40} \mathrm{Ar} /{ }^{39} \mathrm{Ar}$ isochron ages and the IMMAB4 geomagnetic model [22], we believe that the older group of transitional directions (DG4-8 in Figure 6 and Figure 8) correspond to a geomagnetic event within the late Matuyama chron. This event dated at $862 \pm 51$ ka could correspond to the Kamikatsura event. The overlying flows (DG9-17 in Figure 6 and Figure 8), isotopically dated at $787 \pm 40 \mathrm{ka}$, would have recorded only the last stage of the Matuyama-Brunhes reversal, showing a N-T-(N) swing in the VGP path just before achieving 
the full polarity reversal. In this scenario, we thus consider that no Brunhes normal direction is recorded in the Tjörnes lava pile.

3. The present study emphasizes the problem to determine absolute paleointensity from subaerial lava flows with the conventional Thellier and Thellier [30]'s method, and stresses the need to develop and validate from theoretical considerations new paleointensity procedures which will be independent of the domain state.

\section{Appendix A : Supplementary data}

Supplementary data associated with this article can be found, in the online version, at doi:10.1016/j.epsl.2011.07.026 The auxiliary material provided with this paper archives in Table S1 the individual flow average directions with dispersion statistics and the coordinates of the corresponding Virtual Geomagnetic Pole (VGP). Table S2 contains the directional group analysis. Table S3 contains the individual paleointensity determination with the statistical parameters. Table S4 contains the summary of $40 \mathrm{Ar} / 39 \mathrm{Ar}$ furnace incremental heating experiments and Table S5 contains the complete listing of ${ }^{40} \mathrm{Ar} /{ }^{39} \mathrm{Ar}$ data from the samples incrementally heated. Figure S1 represents the equal area projections of the average direction for each lava flow comparing the directional variation curve in each section. Figure S2 illustrates examples of accepted paleointensty diagrams while Figure S3 illustrates examples of rejected paleointensity diagrams. Figure S4 illustrates the variations in virtual dipole moment (VDM) inferred from IMMAB4 model and from data.

\section{Acknowledgments}

We thanks Michel Prévot for scientific discussions, Thierry Poidras, Patrick Nicol and MarieElodie Labry for technical help during laboratory experiments. Sylvie Raynaud provided valuable references. We want to give a special thanks to Leo Kristjansson who kindly helped us to prepare the field trip for sampling. FORC measurements were carried out at the CEREGE institute, we are grateful to Pierre Rochette for the use of this facility. Roman Leonhardt is thanked for providing us with the computer code for the IMMAB4 model. This work was partially supported by the CNRS-INSU. Singer's research on paleomagnetism has been supported by US NSF grants EAR0337684 and EAR-0943584. We thank Cor Langereis and Roman Leonhardt for their thorough review and constructive comments.

\section{References}

[1] L. Kristjánsson, H. Jóhannesson, J. Eiríksson, and A.I. Gudmundsson. Brunhes-Matuyama paleomagnetism in three lava sections in Iceland. Can. J. Earth Sci., 25(2):215-225, 1988.

[2] L. Kristjánsson. Some statistical properties of palaeomagnetic directions in Icelandic lava flows. Geophys. J. R. astr. Soc., 80:57-71, 1985.

[3] B. M. Clement. Dependance of the duration of geomagnetic polarity reversal on site latitude. Nature, 428(6983):637-640, 2004.

[4] J. E. T. Channell, D. A. Hodell, B. S. Singer, and C. Huang. Reconciling astrochronological and ${ }^{40} \mathrm{Ar} /{ }^{39} \mathrm{Ar}$ ages for the Matuyama-Brunhes boundary and late Matuyama chron. Geochem. Geophys. Geosyst., 11:Q0AA12, 2010.

[5] G. A Glatzmaier and P. H. Roberts. A three-dimensional convective dynamo solution with rotating and finitely conducting inner core and mantle. Phys. Earth Planet. Inter., 91:63-75, 1995.

[6] J. Wicht and A. Tilgner. Theory and modeling of planetary dynamos. Space Sci. Rev., 152:501-542, 2010. 
[7] J. Aubert, S. Labrosse, and C. Poitou. Modelling the palaeo-evolution of the geodynamo. Geophys. J. Int., 179:1414-1428, 2009.

[8] R. S. Coe and G. A. Glatzmaier. Symmetry and stability of the geomagnetic field. Geophys. Res. Lett., 33:L21311, 2006.

[9] P. Driscoll and P. Olson. Polarity reversals in geodynamo models with core evolution. Earth Planet. Sci. Lett., 282:24-33, 2009.

[10] H. Amit, R. Leonhardt, and J. Wicht. Polarity reversals from paleomagnetic observations and numerical dynamo simulations. Space Sci. Rev., 155:293-335, 2010.

[11] M. R. E. Proctor and D. Gubbins. Analysis of geomagnetic directional data. Geophys. J. Int., 100:69-77, 1990.

[12] A. Chauvin, P. Roperch, and R. A. Duncan. Records of geomagnetic reversals from volcanic islands of French Polynesia, 2. Paleomagnetic study of a flow sequence (1.2-0.6 Ma) from the island of Tahiti and discussion of reversal models. J. Geophys. Res., 95:2727-2752, 1990.

[13] B. S. Singer, K. A. Hoffman, A. Chauvin, R. S. Coe, and M. S. Pringle. Dating transitionally magnetized lavas of the late Matuyama chron: Toward a new ${ }^{40} \mathrm{Ar} /{ }^{39} \mathrm{Ar}$ timescale of reversals and events. J. Geophys. Res., 104(B1):679-693, 1999.

[14] L. L. Brown, J. C. Pickens, and B. S. Singer. Matuyama-Brunhes transition recorded in lava flows of the chilean Andes; evidence for dipolar fields during reversals. Geology, 22(4):299-302, 1994.

[15] L. L. Brown, B. S. Singer, J. C. Pickens, and B. R. Jicha. Paleomagnetic directions and ${ }^{40} \mathrm{Ar} /{ }^{39} \mathrm{Ar}$ ages from the Tatara - San Pedro volcanic complex, chilean Andes; lava record of a Matuyama-Brunhes precursor? J. Geophys. Res., 109(B12101), 2004.

[16] M.N. Gratton, J. Shaw, and L. L. Brown. Absolute palaeointensity variation during a precursor to the Matuyama-Brunhes transition recorded in chilean lavas. Physics of the Earth and Planetary Interiors, 162(1-2):61 - 72, 2007.

[17] R. S. Coe, B. S. Singer, M. S. Pringle, and X. Zhao. Matuyama-Brunhes reversal and Kamikatsura event on Maui: paleomagnetic directions, ${ }^{40} \mathrm{Ar} /{ }^{39} \mathrm{Ar}$ ages and implications. Earth Planet. Sci. Lett., 222:667-684, 2004.

[18] X. Quidelleur, J. Carlut, V. Soler, J-P. Valet, and P. Y. Gillot. The age and duration of the Matuyama-Brunhes transition from new K-Ar data from la Palma (Canary islands) and revisited (super 40) ar/ (super 39) ar ages. Earth Planet. Sci. Lett., 208(3-4):149-163, 2003.

[19] B. S. Singer, M. K. Relle, K. A. Hoffman, A. Battle, C. Laj, H. Guillou, and J. C. Carracedo. Ar/ar ages from transtionnally magnetized lavas on La Palma, Canary islands, and the geomagnetic instability timescale. J. Geophys. Res., 107(B11), 2002.

[20] J. Carlut, X. Quidelleur, V. Courtillot, and G. Boudon. Paleomagnetic directions and K/Ar dating of 0 to $1 \mathrm{Ma}$ lava flows from La Guadeloupe island (french west Indies): Implications for time-averaged field models. J. Geophys. Res., 105(B1):835-849, 2000.

[21] B. S. Singer, K. A. Hoffman, R. S. Coe, L. L. Brown, B. R. Jicha, M. S. Pringle, and A. Chauvin. Structural and temporal requirements for geomagnetic field reversal deduced from lava flows. Nature, 434:633-636, 2005.

[22] R. Leonhardt and K. Fabian. Paleomagnetic reconstruction of the global geomagnetic field evolution during the Matuyama/Brunhes transition: Iterative bayesian inversion and independent verification. Earth Planet. Sci. Lett., 253(1-2):172 - 195, 2007.

[23] S. Garcia and D. Dhont. Structural analysis of the Húsavík-Flatey transform fault and its relationships with the rift system in Northern Iceland. Geodin. Acta, 18(1):31-41, 2005. 
[24] J. Eiríksson. Lithostratigraphy of the upper Tjörnes sequence, north Iceland: The Breidavík group. Acta Naturalia Islandica, 29:37 pp, 1981.

[25] L. Kristjánsson. A reconnaissance study of paleomagnetic directions in the Tjörnes beds, northern Iceland. Jökull, 54:57-63, 2004.

[26] R. R. Doell. Palaeomagnetic studies of icelandic lava flows. Geophys. J. R. Astron. Soc., 26:459-479, 1972 .

[27] J. Eiríksson, A. I. Gudmundsson, L. Kristjánsson, and K. Gunnarsson. Palaeomagnetism of pliocene-pleistocene sediments and lava flows on Tjörnes and Flatey, North Iceland. Boreas, 19:39-55, 1990.

[28] E. Thellier and O. Thellier. Recherches géomagnétiques sur les coulées volcaniques d'Auvergne. Ann. Geophys., 1:37-52, 1944.

[29] M. Prévot. Some aspects of magnetic viscosity on subaerial and submarine volcanic rocks. Geophys. J. R. Astr. Soc., 66:169-192, 1981.

[30] E. Thellier and O. Thellier. Sur l'intensité du champ magnétique terrestre dans le passé historique et géologique. Ann. Geophys., 15:285-376, 1959.

[31] R. P. Pike, A. P. Roberts, and K. L. Verosub. Characterizing interactions in fine magnetic particle systems using first order reversal curves. J. Appl. Phys., 85:6660-6667, 1999.

[32] S. E. Haggerty. Oxide textures; a mini-atlas. Reviews in Mineralogy and Geochemistry, 25(1):129-219, 1991.

[33] M. Prévot, A. Lecaille, and E. A. Mankinen. Magnetic effects of maghemitization of oceanic crust. J. Geophys. Res., 86:4009-4020, 1981.

[34] A. A. Kosterov. Magnetic properties of subaerial basalts at low temperature. Earth Planets Space, 53:883-892, 2001.

[35] A. R. Muxworthy and F. Heider. Rock magnetic investigation of historical lavas used in palaeointensity studies. Studia geoph. et geod., 45:283-296, 2001.

[36] A. Kontny, C. Vahle, and H. De Wall. Characteristic magnetic behavior of subaerial and submarine lava units from the hawaiian scientific drilling projet (hsdp-2). Geochem. Geophys. Geosyst., 4(2), 2003.

[37] W. E. Senanayake and M. W. McElhinny. Hysteresis and susceptibility characteristics of magnetite and titanomagnetite: Interpretation of results from basaltic rocks. Phys. Earth Planet. Inter., 26:47-55, 1981.

[38] D. Lattard, R. Engelmann, A. Kontny, and U. Sauerzapf. Curie temperatures of synthetic titanomagnetites in the Fe-Ti-O system: Effects of composition, crystal chemistry, and thermomagnetic methods. J. Geophys. Res., 111(B12S28), 2006.

[39] J. C. W. Richards, J. R. O'Donovan, Z. Hauptman, and W. O'Reilly. A magnetic study of titanomagnetite substituted by magnesium and aluminium. Phys. Earth Planet. Inter., 7:437-444, 1973.

[40] A.F. Buddington and D.H. Lindsley. Iron-Titanium oxide minerals and synthetic equivalents. J. Petrol., 5:310-357, 1964.

[41] M. Prévot, E. A. Mankinen, R. S. Coe, and C. S. Grommé. The Steens Mountain (Oregon) geomagnetic polarity transition. 2. Field intensity variations and discussion of reversal models. J. Geophys. Res., 90:10417-10448, 1985.

[42] R. Leonhardt, C. Heunemann, and D. Krása. Analysing absolute paleointensity determinations: Acceptance criteria and the software Thelliertool4.0. Geochem. Geophys. Geosyst. $5(12), 2004$. 
[43] R. S. Coe, S. Grommé, and E. A. Mankinen. Geomagnetic paleointensities from radiocarbondated lava flows on Hawaii and the question of the Pacific nondipole low. J. Geophys. Res., 83:1740-1756, 1978.

[44] P. A. Selkin and L. Tauxe. Long term variations in palaeointensity. Philos. Trans. R. Soc. A-Math. Phys. Eng. Sci., 358(1768):1065-1088, 2000.

[45] G. Plenier, P. Camps, R. S. Coe, and M. Perrin. Absolute palaeointensity of Oligocene (24-30 Ma) lava flows from the Kerguelen Archipelago (southern Indian Ocean). Geophys. J. Int., 154:877-890, 2003.

[46] R. S. Coe, S. Grommé, and E. A. Mankinen. Geomagnetic paleointensities from excursion sequences in lavas on Oahu, Hawaii. J. Geophys. Res., 89:1059-1069, 1984.

[47] A. Goguitchaichvili, M. Prévot, J. Thompson, and N. Roberts. An attempt to determine the absolute geomagnetic field intensity in Southwestern Iceland during the Gauss-Matuyama reversal. Phys. Earth Planet. Inter., 115:53-66, 1999.

[48] P. R. Renne, C. C. Swisher, A. L. Deino, D. B. Karner, T. Owens, and D. J. DePaolo. Intercalibration of standards, absolute ages and uncertainties in ${ }^{40} \mathrm{Ar} /{ }^{39} \mathrm{Ar}$ dating. Chem. Geol., 154:117-152, 1998.

[49] K. F. Kuiper, A. Deino, F. J. Hilgen, W. Krijgsman, P. R. Renne, and J. R. Wijbrans. Synchronizing rock clocks of earth history. Science, 320:500-504, 2008.

[50] B. S. Singer, K. A. Hoffman, E. Schnepp, and H. Guillou. Multiple Brunhes chron excursions recorded in the West Eifel (Germany) volcanics: Support for long-held mantle control over the non-axial dipole field. Physics of the Earth and Planetary Interiors, 169(1-4):28 - 40, 2008.

[51] A. P. Koppers. Ararcalc - software for 40Ar/39Ar age calculations. Comput. Geosci., 28:605$619,2002$.

[52] D. York. Least squares fitting of a straight line with correlated errors. Earth Planet. Sci. Lett., 5:320-324, 1969.

[53] B. S. Singer. Encyclopedia of Geomagnetism and Paleomagnetism, chapter Polarity Transitions: Radioisotopic Dating, pages 834-839. Springer, 2007.

[54] D. E. Champion and M. A. Lanphere. Evidence for a new geomagnetic reversal from lava flows in Idaho: Discussion of short polarity reversals in the Brunhes and late Matuyama polarity chrons. J. Geophys. Res., 93(B10):11,667-11,680, 1988.

[55] K. O. Takatsugi and M. Hyodo. A geomagnetic excursion during the late Matuyama chron, the Osaka group, southwest Japan. Earth Planet. Sci. Lett., 136:511-524, 1995.

[56] M. Dekkers and H. Böhnel. Reliable absolute palaeointensities independent of magnetic domain state. Earth Planet. Sci. Lett., 248(1-2):508 - 517, 2006.

[57] T. Poidras, P. Camps, and P. Nicol. Controlled atmosphere vibrating thermo-magnetometer (CatVTM) : A new device to optimize the absolute paleointensity determination. Earth Planet Space, 61(1):101-110, 2009.

[58] K. Fabian and R. Leonhardt. Multiple-specimen absolute paleointensity determination: An optimal protocol including pTRM normalization, domain-state correction, and alteration test. Earth Planet. Sci. Lett., 207:84-94, 2010.

[59] A. R. Muxworthy. Revisiting a domain-state independent method of palaeointensity determination. Physics of the Earth and Planetary Interiors, 179(1-2):21 - 31, 2010. 


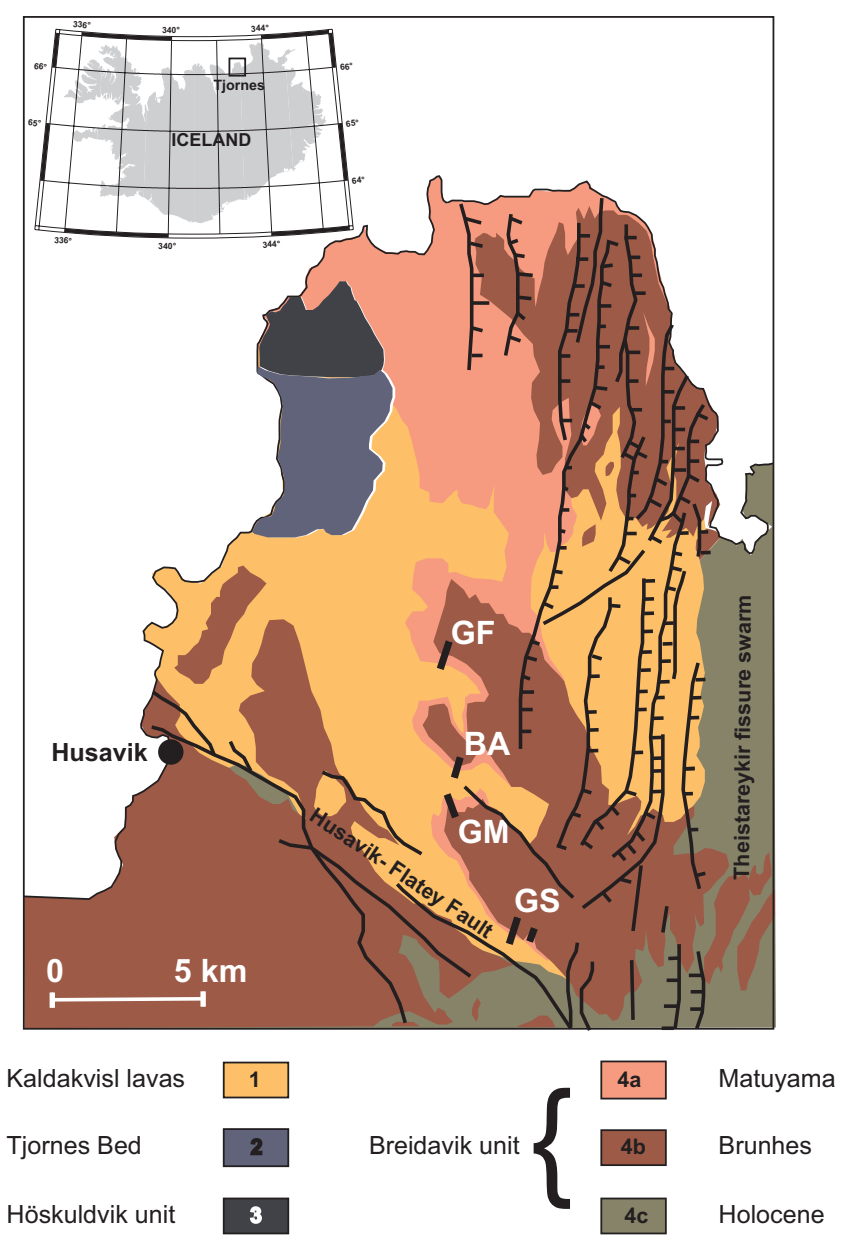

Figure 1: Simplified geological map of Tjörnes peninsula redrawn from Kristjansson et al. [1], and Garcia et al. [23]. The main structural elements and the lithological units are represented. (1) Kaldakvísl lavas, (2) Tjörnes beds, (3) Höskuldsvík unit, and (4) Breiðavík unit, in which Matuyama (4a), Brunhes (4b) and Holocene (4c) formations are distinguished. Letters denote the locations of sampled cross sections. 

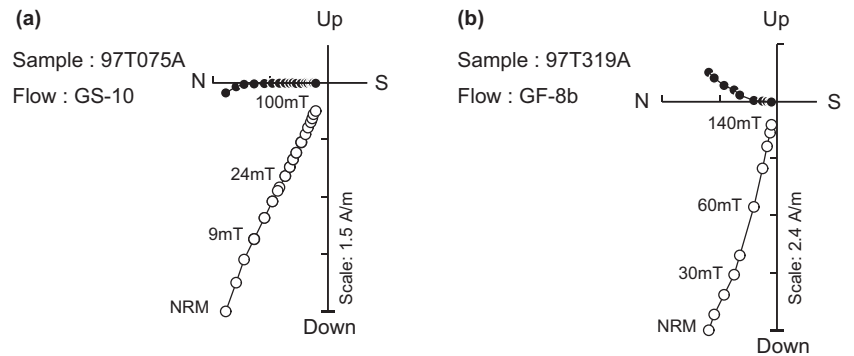

(c)

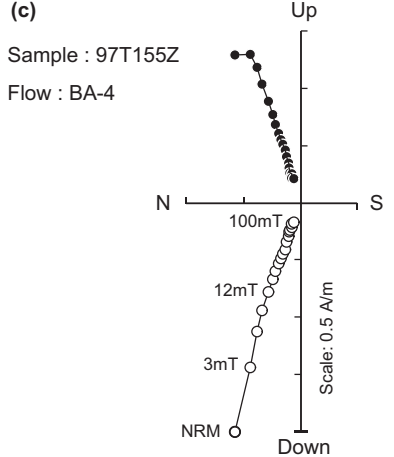

(d)
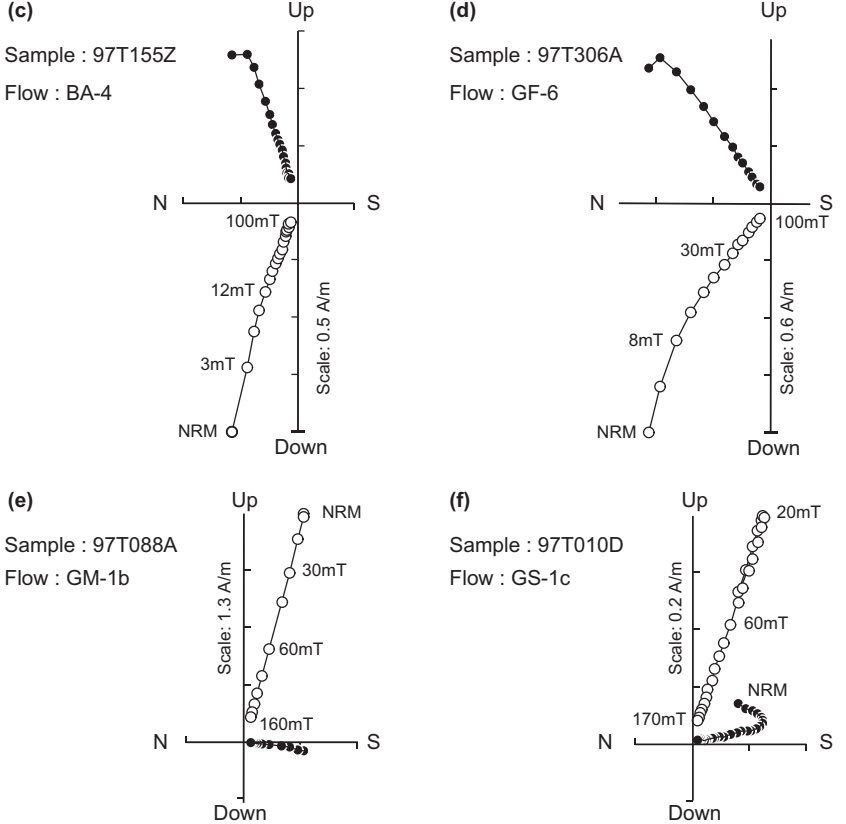

Figure 2: Example of vector endpoint diagrams of progressive AF demagnetizations for normal $(\mathrm{a}, \mathrm{b})$, intermediate $(\mathrm{c}, \mathrm{d})$, and reversed $(\mathrm{e}, \mathrm{f})$ directions. Projection are in tilt-corrected coordinates. Solid (open) symbols represent projection into horizontal (vertical) planes. These diagrams show that the ChRM are easily isolated even when secondary components are present $(b, d, f)$. 


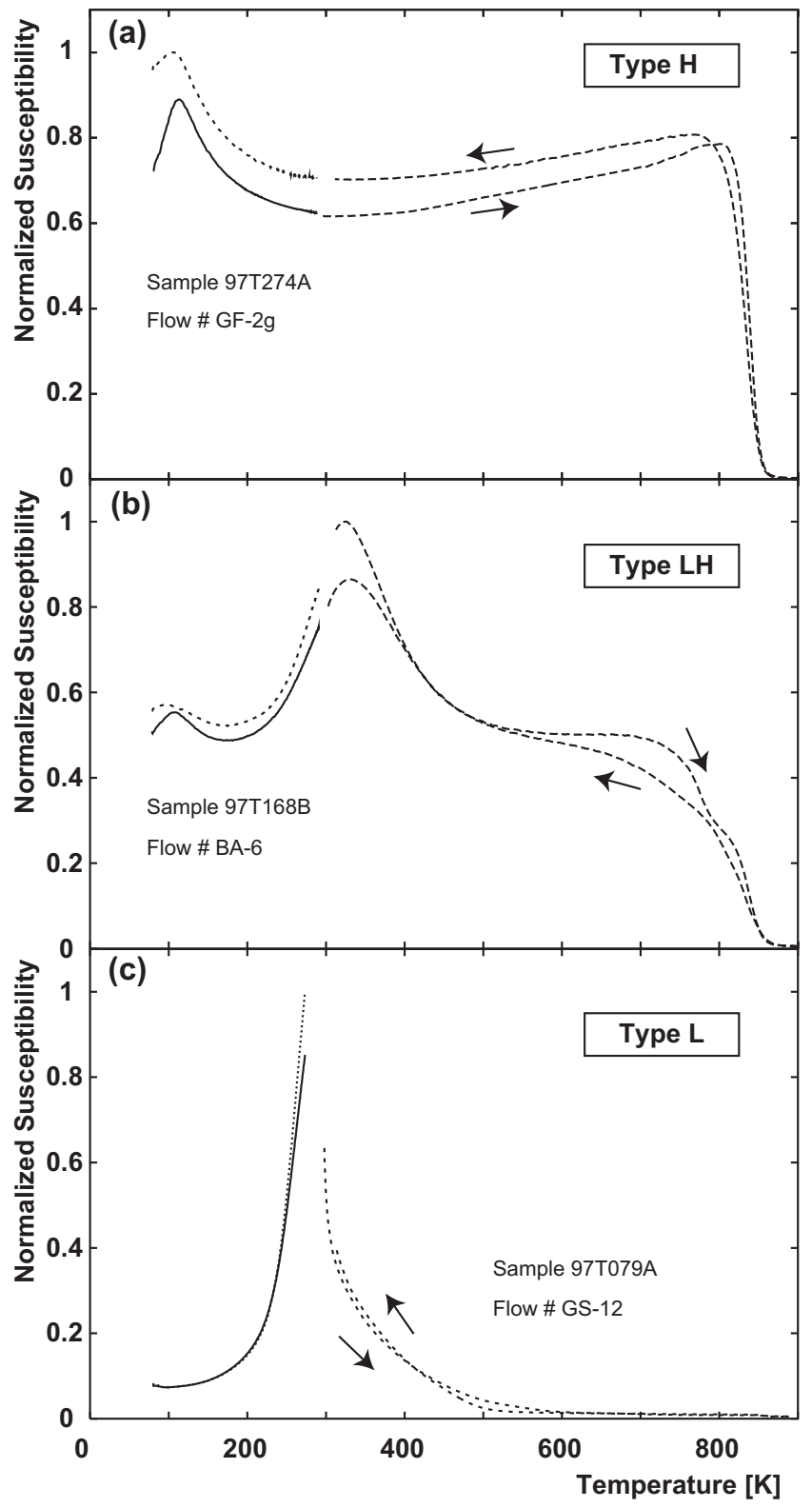

Figure 3: Representative examples of low-field susceptibility versus temperature curves (k-T curves). Susceptibility values are normalized to the maximum susceptibility. Solid (dotted) lines are the first (last) heating curves from liquid nitrogen temperature. Dashed lines correspond to the heating-cooling curves cycles at high temperatures. (a),(b),(c) illustrate the reversible case for type H, LH, and L curves, respectively (see text). 

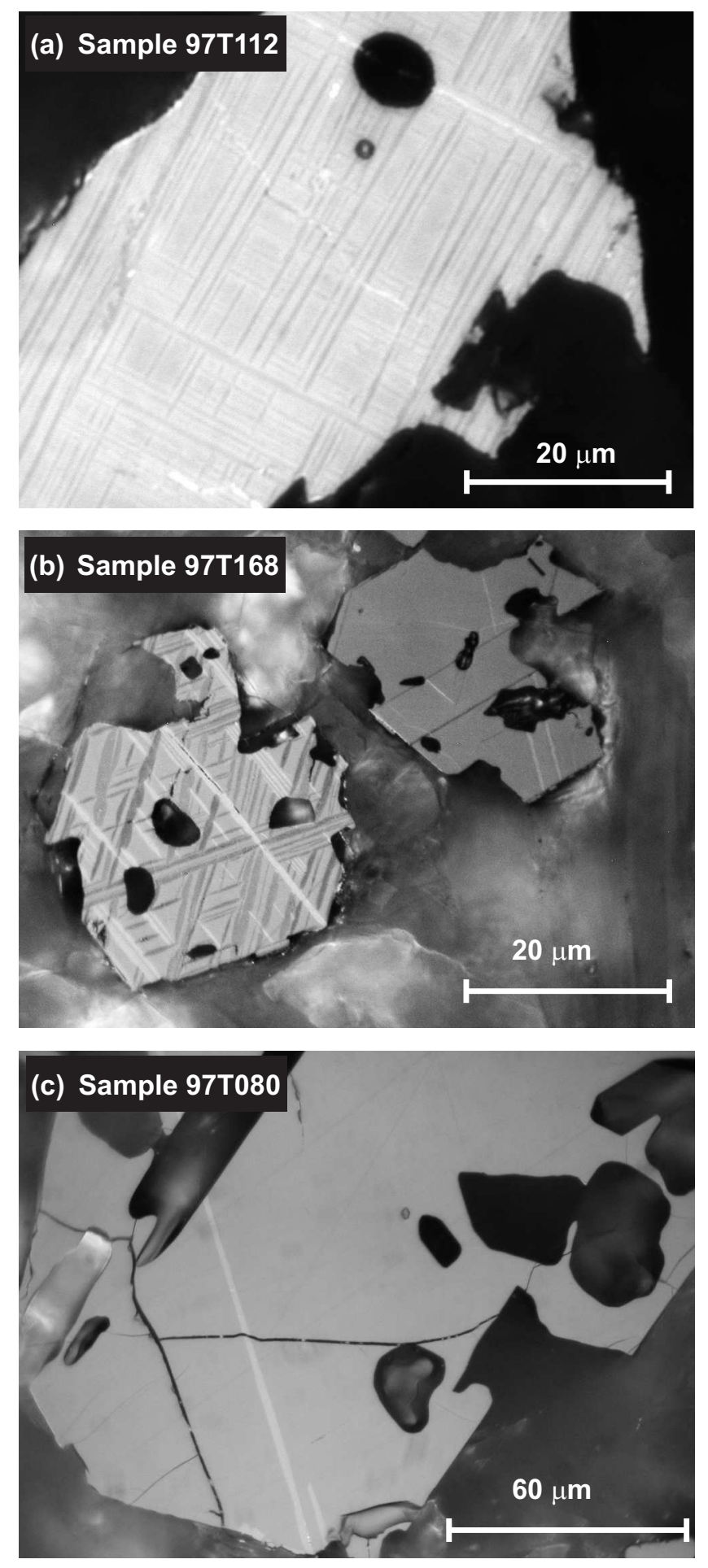

Figure 4: Ore microscopic study carried out under oil immersion. (a) Type H samples. Subhedral grain of titanomagnetite with ilmenite trellis lamellae in a rectangular pattern which could results from the direction of the sectioning (oxidation stage C3-C4). (b) Type LH sample. Two generations of titanomagnetites in a very close vinicity showing different stage of oxidation. The grain on the right is a homogeneous Ti-rich titanomagnetite with few exsolved thin ilmenite lamellae (oxidation stage C1-C2). The grain on the left shows densely ilmenite intergrowths in titanomagnetite (oxidation stage C3-C4). The ilmenite lamellae are along the grain boundaries for the both crystals. (c) Type L sample. Optically homogeneous titanomagnetite with only one ilmenite lath that extends to the edges of the crystal and a second (lower part) internally truncated (oxidation stage C1-C2). 

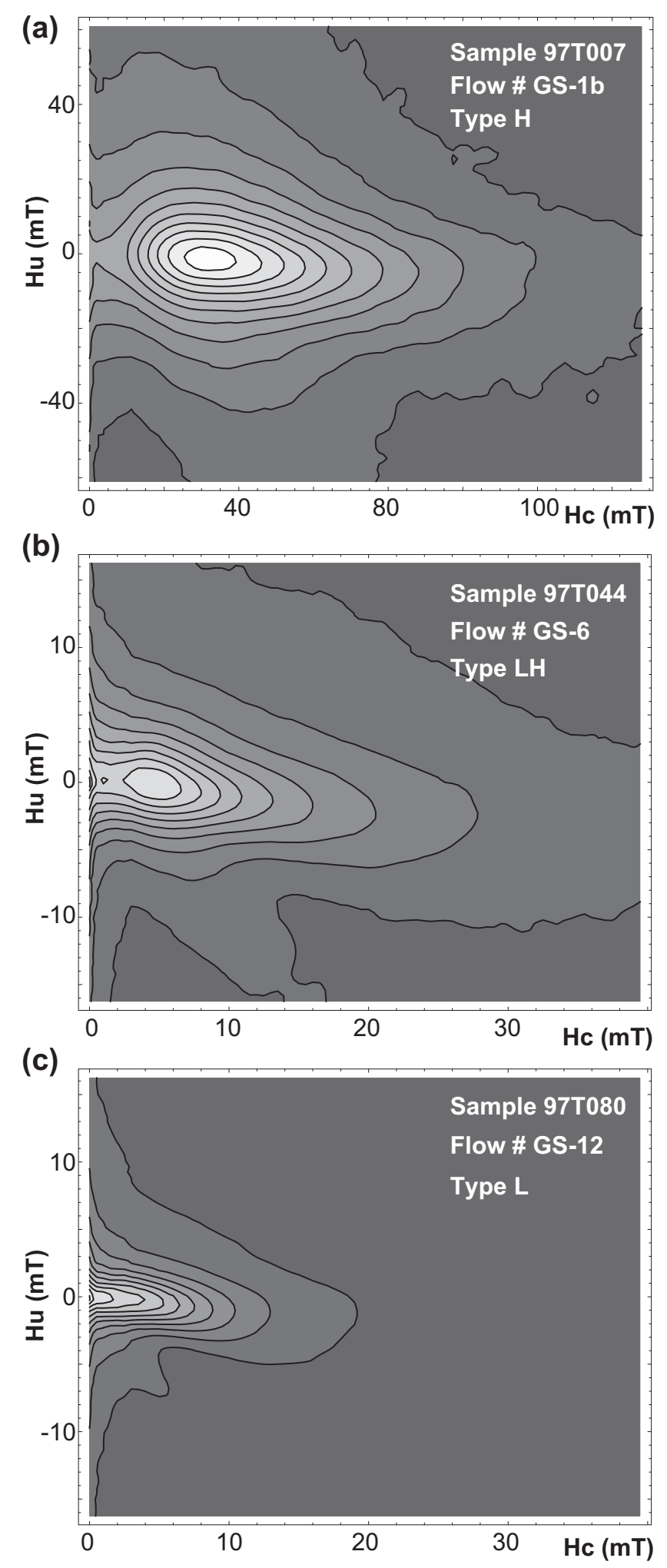

Figure 5: FORC diagrams for the three sample types defined upon the characteristics of the k-T curves. These diagrams indicate that the magnetic grains are mainly (a) in a weak-interacting SD state for sample of Type H, and (c) in a MD state for sample of type L. Sample of type LH (b) shows clearly a mixture of MD and SD-PSD contribution. The FORC diagrams are shown with the same scale for $\mathrm{Hc}$ and $\mathrm{Hu}$ axes. The smoothing factor is 3 in each diagram. 


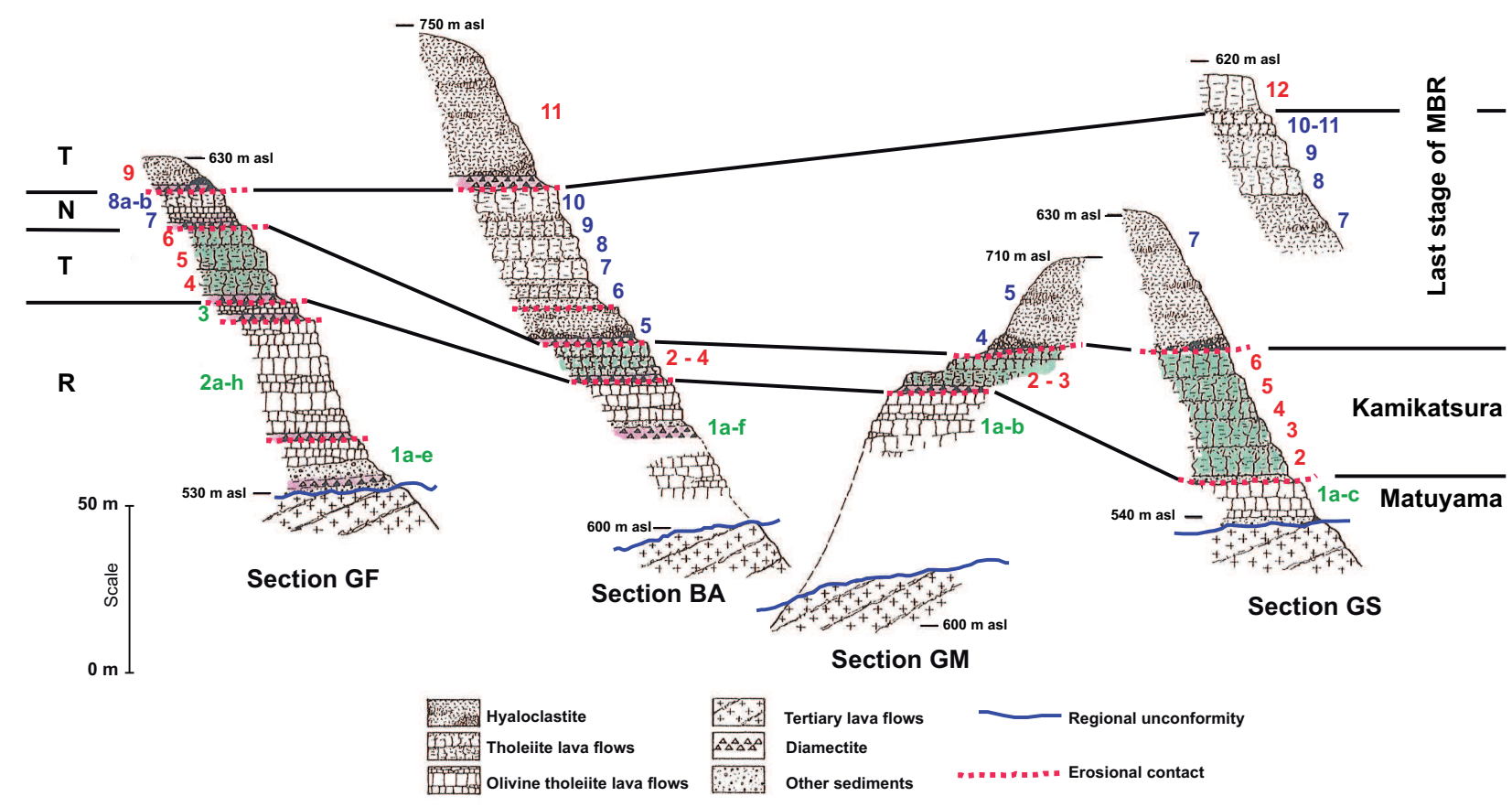

Figure 6: Stratigraphic relationships of the lava flows on Tjörnes peninsula. This figure is redrawn from Fig. 5 in Krisjansson et al. [1]. 


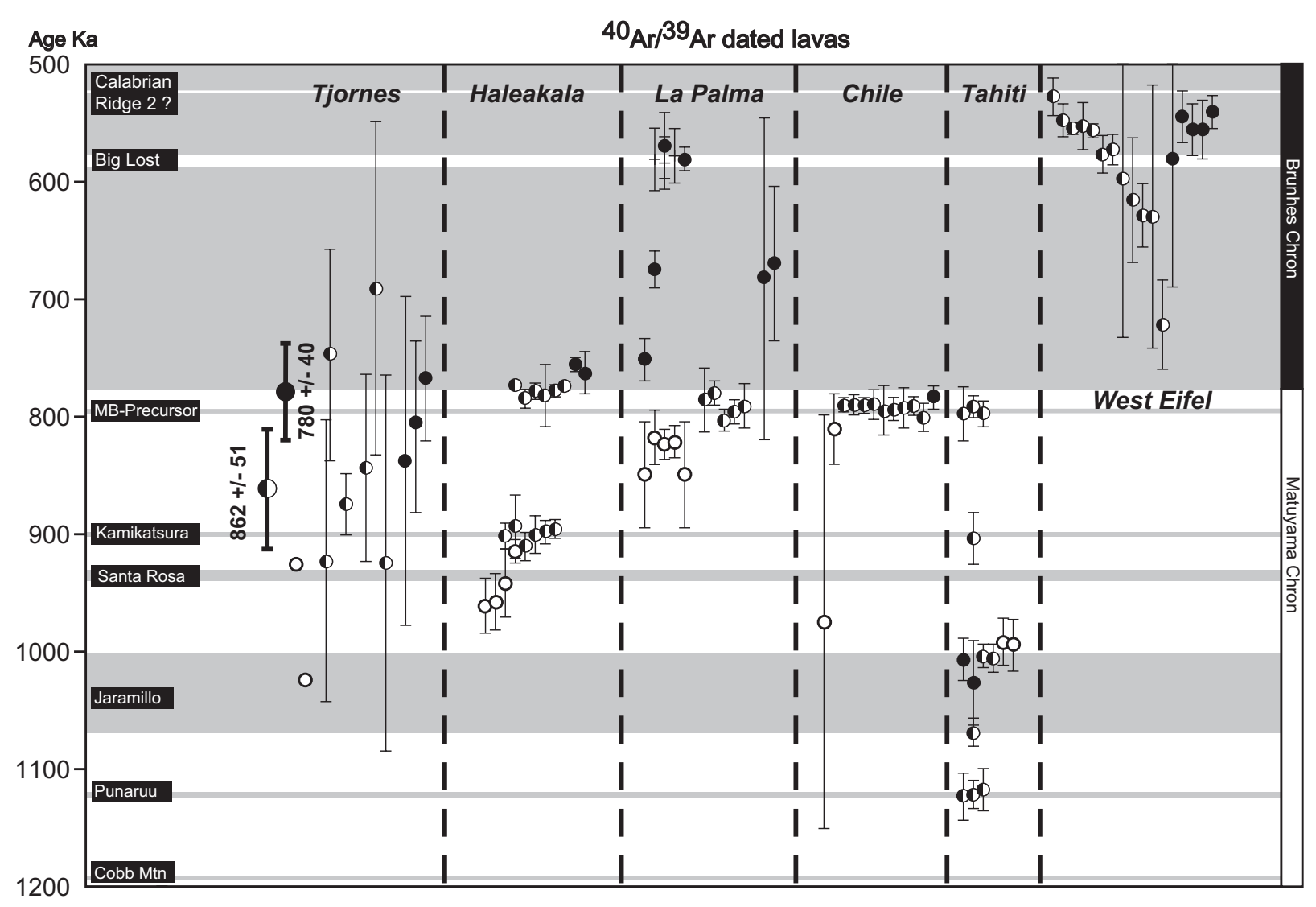

Figure 7: ${ }^{39} \mathrm{Ar} /{ }^{40} \mathrm{Ar}$ ages of normally (black circles), reversely (white circles), and transitionally (black and white circles) magnetized lava flows, obtained with the same analytical technique and all relative to 28.02 Ma Fish Canyon sanidine standard, with $2 \sigma$ analytical uncertainties shown; Tjörnes (this study), Haleakala [17], La Palma, Canary Islands [19], Tatara-San Pedro, Chile [15], Panaruu Valley, Tahiti [13], and West Eifel, Germany [50]. Uncertainties are not reported for the Tjörnes reversely magnetized flows because they are too large. Weighted average age of older group of transitionally and normally magnetized flows from Tjörnes are represented by means of larger symbols and uncertainties in bold solid lines. 


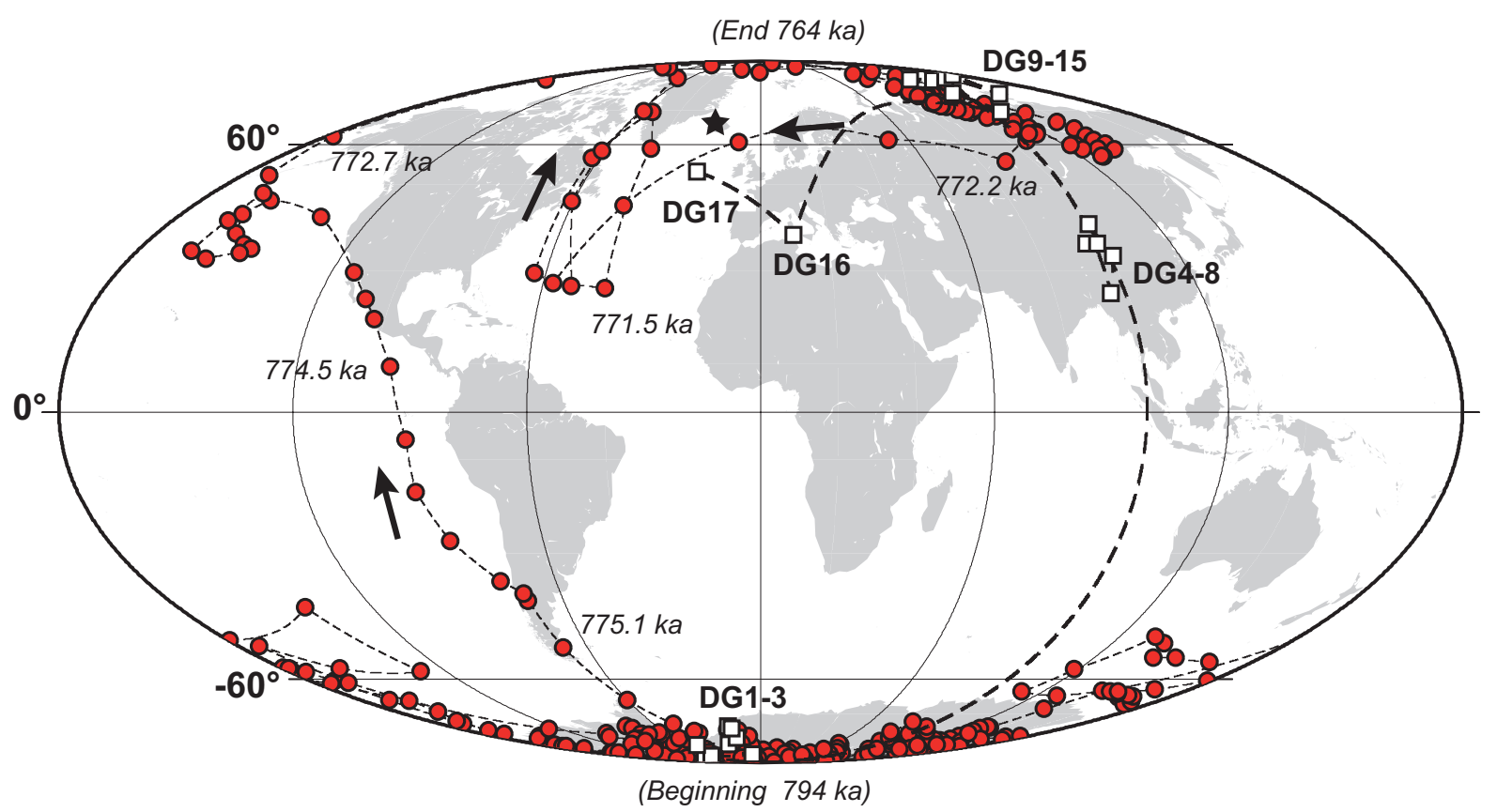

Figure 8: Virtual geomagnetic pole (VGPs) locations for the directional groups for Tjörnes volcanic sequence (squares). Also shown are the VGPs path (circles) with ages predicted from IMMAB4 model [22] of the Matuyama-Brunhes reversal for Tjörnes location (Black star). 


\section{Supplementary Material}

The following are the supplementary materials related to this article: 


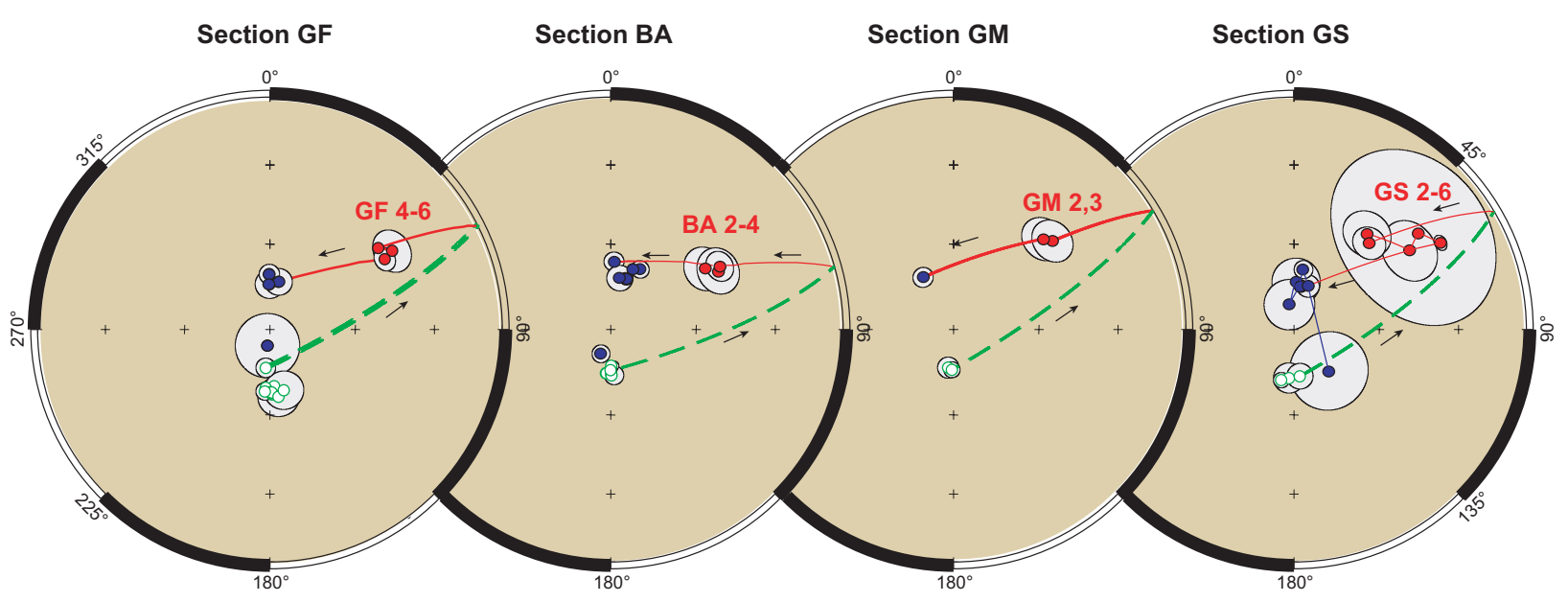

Figure 1: Equal area projections of the average direction for each lava flow comparing the directional variation curve in each section. Filled and open circles represent positive and negative inclinations, respectively. 95\% confidence circles are shown in grey when they are not smaller than the plotted symbols. 

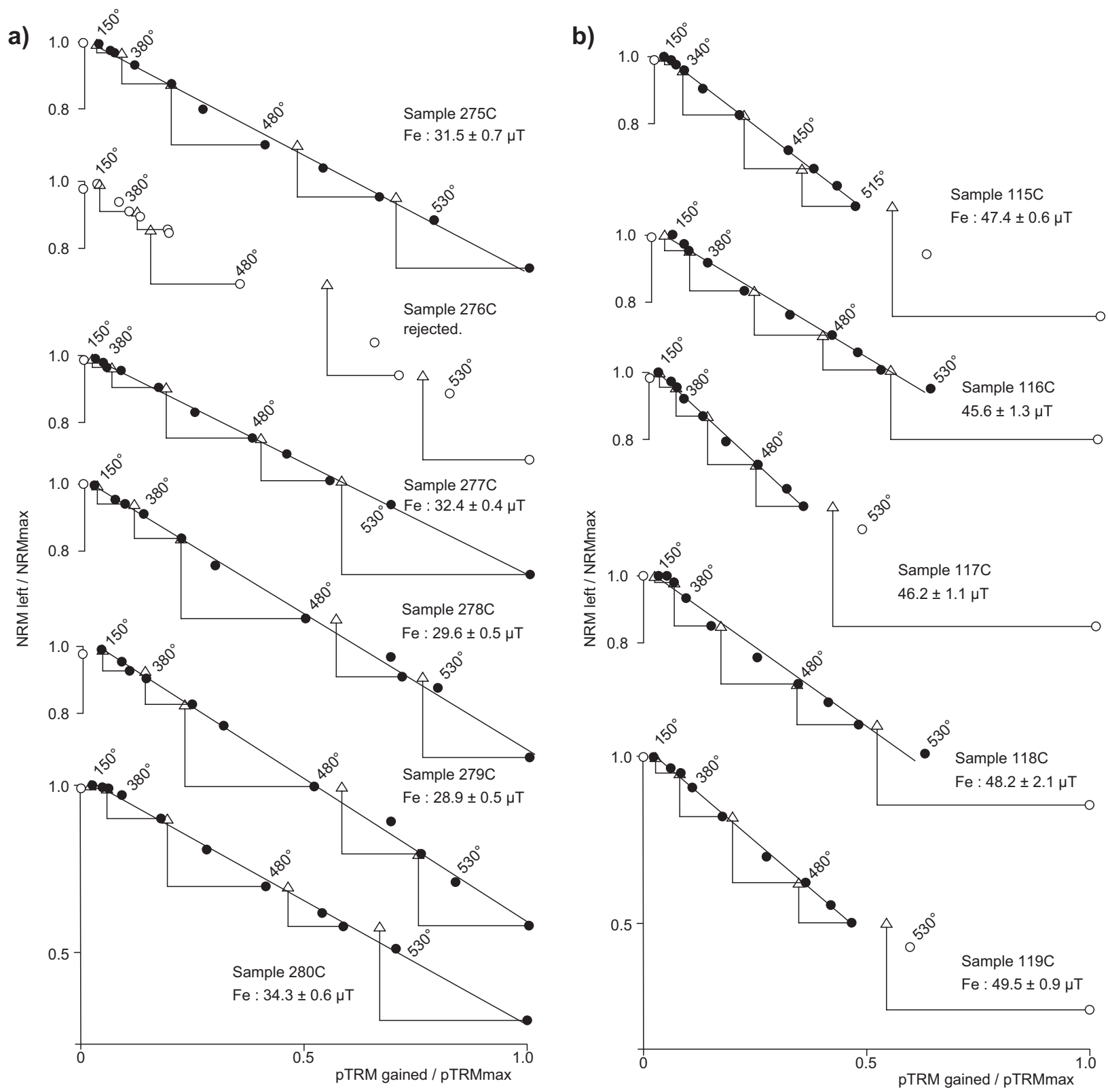

Figure 2: Composite Arai diagrams for samples (a) from flow GF-2f, left column, and (b) from flow BA-1b, right column. Solid (open) circles are NRM-TRM points accepted (rejected) to calculate the least squares line used to estimate the paleointensity. Triangles denote the pTRM checks. In these diagrams, NRM and TRM are normalized by the NRM max and TRM max, respectively, and the temperature are in degrees Celsius. We did not use the initial part of these diagrams since it is affected by a secondary magnetization, certainly of viscous origin. Additionally, we did not use the last heating steps for samples from flow BA-1b (b) since they are obviously affected by an increase in pTRM acquisition capacity. Sample $276 \mathrm{C}$ is rejected because the pTRM check at $480^{\circ} \mathrm{C}$ is negative. 

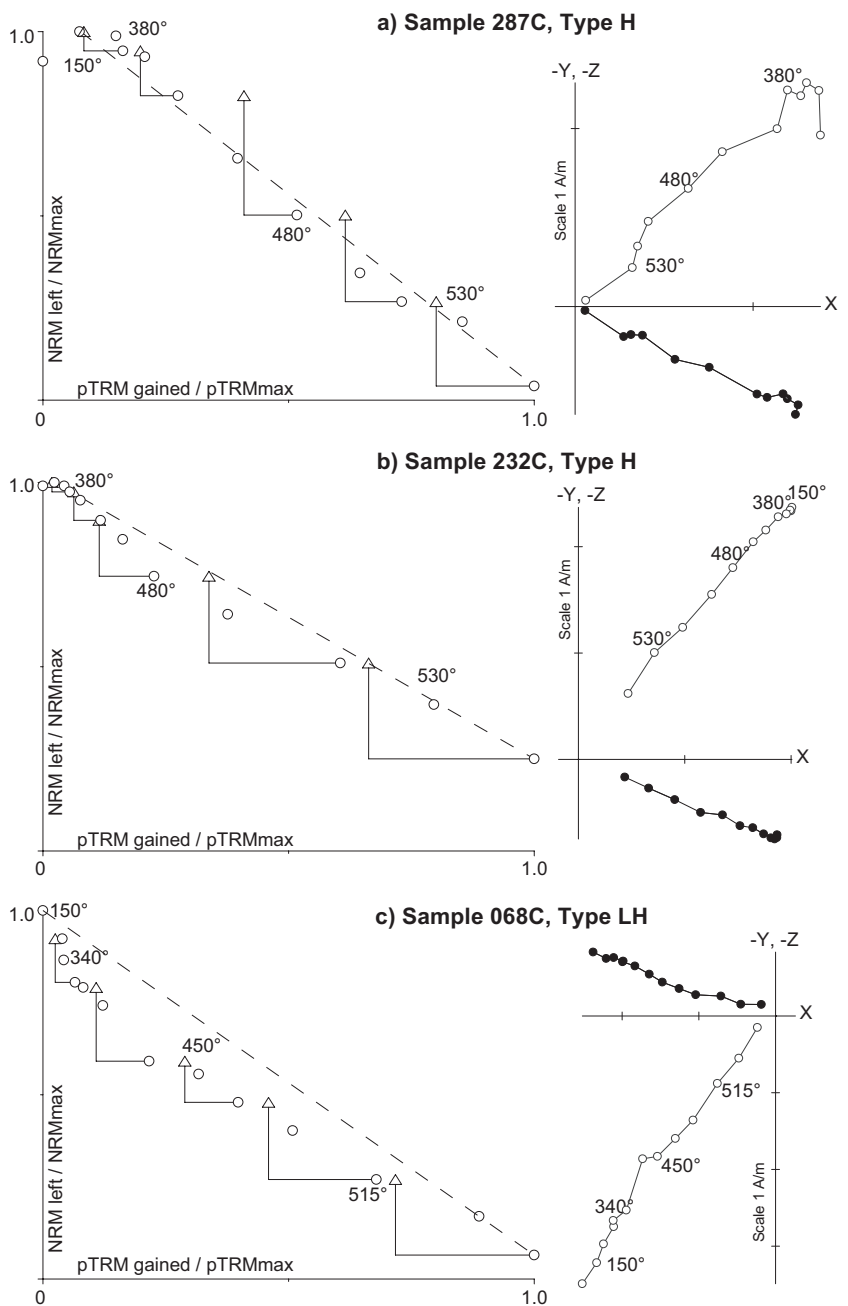

Figure 3: Example of rejected paleointensity diagrams (left column) with their associated vector endpoint diagrams (right column). These samples are rejected on the basis of (a) negative pTRMchecks, or (b) and (c) curved NRM-TRM diagrams. In the Arai plot, open circles are NRM-TRM points and triangles denote the pTRM checks. The dashed lines connect the first and the last point of the ChRM interval, that is, they do not correspond to the best-fit lines. They are drawn simply to assess the linearity of the plot. In the vector endpoint diagrams, solid (open) symbols represent projection into the sample coordinates $\mathrm{X}, \mathrm{Y}(\mathrm{X}, \mathrm{Z})$. 


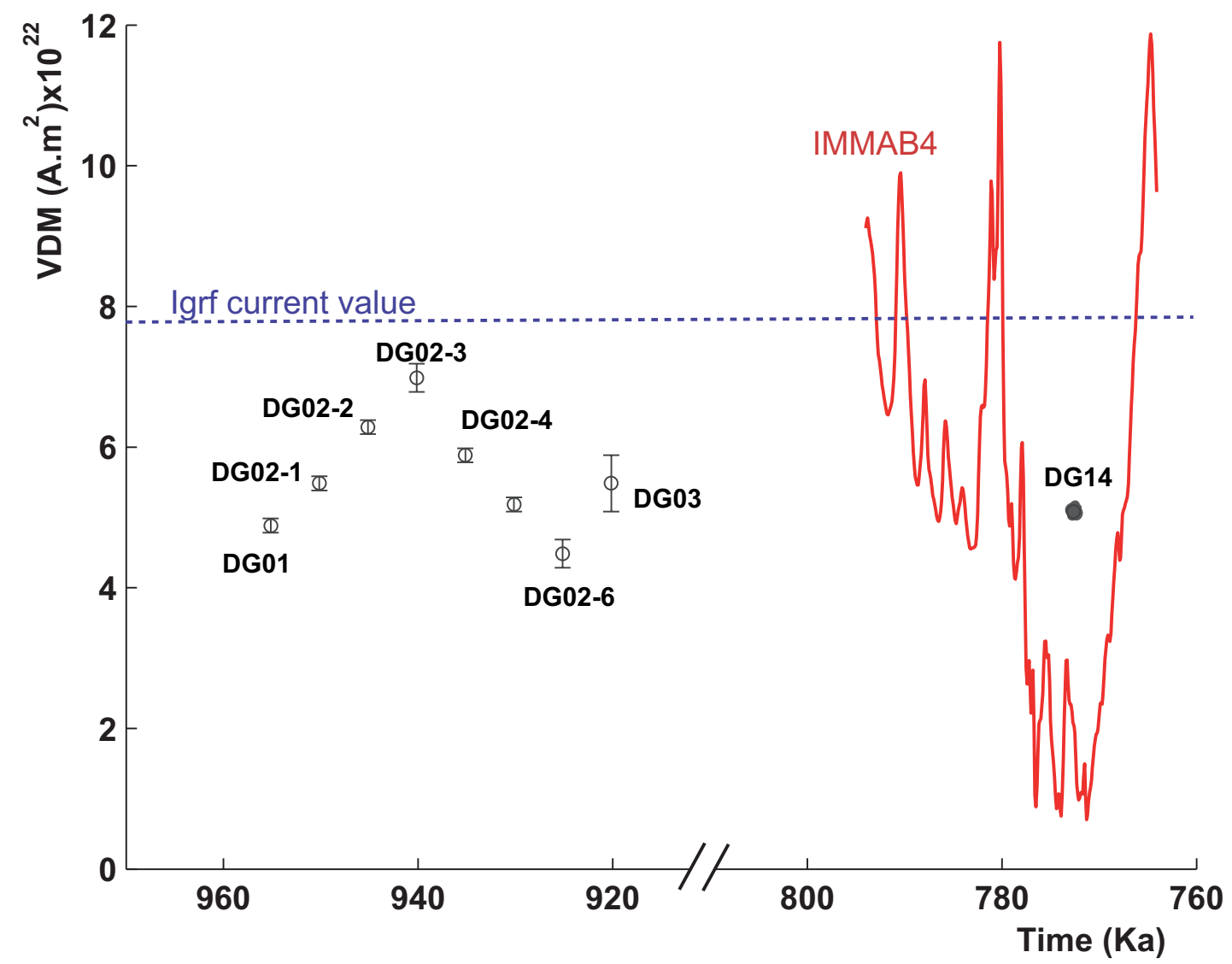

Figure 4: Variations in virtual dipole moment (VDM) inferred from IMMAB4 model [22] for Tjörnes location (Black solid curve) and from the paleointensity estimated from reversely (white circles), and normally (black circle) magnetized lava flows from Tjörnes. The horizontal dashed line correspond to the current value of $7.78 \times 10^{22} \mathrm{Am}^{2}$ calculated from the igrf model. The age of DG14 is estimated by comparing its VGP location with the IMMAB4 model outcome (see text). 
Table 1: Directional results and Intensity in a composite stratigraphical succession on Tjörnes.

\begin{tabular}{|c|c|c|c|c|c|c|c|c|c|c|c|c|}
\hline DG & Flow & $\mathrm{N}_{d}$ & $\begin{array}{r}\mathrm{D}, \\
\mathrm{deg}\end{array}$ & $\begin{array}{c}\text { I, } \\
\text { deg }\end{array}$ & $\kappa$ & $\begin{array}{r}\alpha_{95} \\
\text { deg }\end{array}$ & $\begin{array}{c}\phi \\
\operatorname{deg}\end{array}$ & $\begin{array}{c}\lambda \\
\operatorname{deg}\end{array}$ & Type & $\mathrm{N}_{p}$ & $\begin{array}{c}\overline{\mathrm{F}}_{\mathrm{E}} \pm \mathrm{s} . \mathrm{d} . \\
\mu \mathrm{T}\end{array}$ & $\begin{array}{c}\text { VDM } \\
10^{22} \mathrm{Am}^{2} \\
\end{array}$ \\
\hline \multicolumn{13}{|c|}{ Intermediate Polarity } \\
\hline 17 & gf9,ba11 & 10 & 194.2 & 83.1 & 151 & 3.9 & 337.6 & 53.1 & $\mathrm{~L}, \mathrm{~L}^{i}$ & & & \\
\hline 16 & $\mathrm{gs} 12$ & 6 & 136.7 & 71.2 & 25 & 13.7 & 9.8 & 38.0 & $\mathrm{~L}$ & & & \\
\hline \multicolumn{13}{|c|}{ Normal Polarity } \\
\hline 15 & gs $11, \mathrm{ba} 9$ & 14 & 21.8 & 66.3 & 222 & 2.7 & 119.0 & 69.4 & $\mathrm{~L}, \mathrm{H}^{i}$ & & & \\
\hline 14 & gs10,ba8 & 13 & 17.6 & 70.0 & 286 & 2.5 & 118.6 & 75.5 & $\mathrm{H}, \mathrm{H}^{i}, \mathrm{LH}$ & 1 & 33.8 & 5.08 \\
\hline 13 & gs 9, ba 7 & 12 & 12.2 & 72.7 & 273 & 2.6 & 121.4 & 80.5 & $\mathrm{LH}, \mathrm{LH}^{i}$ & & & \\
\hline 12 & gs $8, \mathrm{ba} 6$ & 10 & 8.4 & 71.7 & 149 & 4.0 & 136.0 & 80.1 & $\mathrm{LH}$ & & & \\
\hline 11 & gf8a,b & 11 & 1.8 & 71.9 & 246 & 2.9 & 156.1 & 81.1 & $\mathrm{LH}^{i}, \mathrm{H}^{i}$ & & & \\
\hline 10 & gf7, ba5 & 10 & 6.8 & 68.3 & 224 & 3.2 & 145.7 & 75.2 & $\mathrm{LH}, \mathrm{LH}^{i}$ & & & \\
\hline 09 & gs7, gm5 & 12 & 356.6 & 72.5 & 80 & 4.9 & 174.3 & 82.0 & $\mathrm{~L}^{i}, \mathrm{LH}^{i}$ & & & \\
\hline \multicolumn{13}{|c|}{ Intermediate Polarity } \\
\hline 08 & gs6 & 6 & 59.6 & 26.8 & 1263 & 1.9 & 95.5 & 25.1 & $\mathrm{LH}, \mathrm{LH}^{i}$ & & & \\
\hline 07 & gs 5 & 5 & 51.9 & 31.9 & 8 & 29.6 & 100.9 & 33.3 & $\mathrm{LH}^{i}$ & & & \\
\hline 06 & gf6, gs $4, \mathrm{ba} 4, \mathrm{gm} 4$ & 24 & 55.3 & 41.7 & 82 & 3.3 & 95.3 & 36.0 & $\mathrm{LH}, \mathrm{LH}^{i}$ & & & \\
\hline 05 & gf5, gs 3, ba 3 & 19 & 52.5 & 39.2 & 32 & 6.1 & 98.5 & 36.1 & $\mathrm{LH}, \mathrm{LH}^{i}$ & & & \\
\hline 04 & $\mathrm{gf} 4, \mathrm{gs} 2, \mathrm{ba} 2, \mathrm{gm} 2$ & 25 & 49.8 & 45.1 & 78 & 3.3 & 99.7 & 40.5 & $\mathrm{LH}, \mathrm{LH}^{i}, \mathrm{~L}$ & & & \\
\hline \multicolumn{13}{|c|}{ Reversed Polarity } \\
\hline 03 & gf3 & 7 & 188.7 & -75.8 & 324 & 3.4 & 287.3 & -85.4 & $\mathrm{H}, \mathrm{LH}$ & 4 & $39.4 \pm 2.8$ & $5.5 \pm 0.4$ \\
\hline $02-6$ & gf2f,gs $1 \mathrm{c}, \mathrm{ba} 1 \mathrm{f}$ & 17 & 182.8 & -71.5 & 265 & 2.2 & 334.2 & -80.4 & $\mathrm{H}$ & 11 & $30.4 \pm 1.3$ & $4.5 \pm 0.2$ \\
\hline $02-5$ & gm1a,b & 9 & 187.3 & -75.5 & 713 & 1.9 & 295.4 & -85.4 & $\mathrm{H}$ & 10 & $36.8 \pm 0.9$ & $5.2 \pm 0.1$ \\
\hline $02-4$ & ba1c,d,e & 15 & 178.5 & -74.3 & 745 & 1.4 & 350.7 & -84.6 & $\mathrm{H}$ & 14 & $41.3 \pm 1.0$ & $5.9 \pm 0.1$ \\
\hline $02-3$ & gs1b, ba1b & 10 & 190.3 & -72.6 & 640 & 1.9 & 307.4 & -80.7 & $\mathrm{H}$ & 9 & $48.1 \pm 1.3$ & $7.0 \pm 0.2$ \\
\hline $02-2$ & gf2c-e,gs1a,bala & 25 & 179.5 & -69.7 & 173 & 2.2 & 343.4 & -77.9 & $\mathrm{H}, \mathrm{LH}$ & 10 & $41.7 \pm 0.7$ & $6.3 \pm 0.1$ \\
\hline $02-1$ & gf $2 a, b$ & 11 & 180.9 & -67.2 & 1104 & 1.4 & 340.9 & -74.0 & $\mathrm{H}$ & 11 & $35.3 \pm 0.4$ & $5.5 \pm 0.1$ \\
\hline 01 & gf1a-g & 48 & 180.1 & -67.7 & 643 & 0.8 & 342.7 & -74.7 & $\mathrm{H}, \mathrm{H}^{i}, \mathrm{LH}^{i}$ & 18 & $31.7 \pm 0.7$ & $4.9 \pm 0.1$ \\
\hline
\end{tabular}

DG is the directional group number assuming the stratigraphic correlation of Eiriksson et al. [27], the additional digit in DG02 indicating subdivisions based on our paleointensity results. DG are listed in stratigraphic order with the youngest on top, oldest on the bottom; Nd is the number of samples used to calculate the mean directions; $\mathrm{D}$ and $\mathrm{I}$ are the mean declination and inclination in tilt adjusted coordinates, respectively; $\kappa$ is the concentration parameter and $\alpha_{95}$ is $95 \%$ confidence cone about average direction in the tilt adjusted coordinates, respectively; $\kappa$ is the concentration parameter and $\alpha_{95}$ is $95 \%$ confidence cone about average direction in the
Fisher statistics; $\phi$ and $\lambda$ are longitude and latitude of corresponding VGP position, respectively; Type is the rock magnetism type (see text for definition) encountered in the DG, superscript $\mathrm{i}$ indicates irreversible KT-curves; $\mathrm{N}_{p}$ is the number of samples used to calculate the mean paleointensity; $\overline{\mathrm{F}}_{\mathrm{E}} \pm$ s.d. is the weighted paleointensity average plus or minus standard error of the mean; VDM is the weighted mean virtual dipole moment. 
Table 2: Summary ${ }^{40} \mathrm{Ar} /{ }^{39} \mathrm{Ar}$ Incremental-Heating Experiments, Tjörnes Peninsula, Iceland

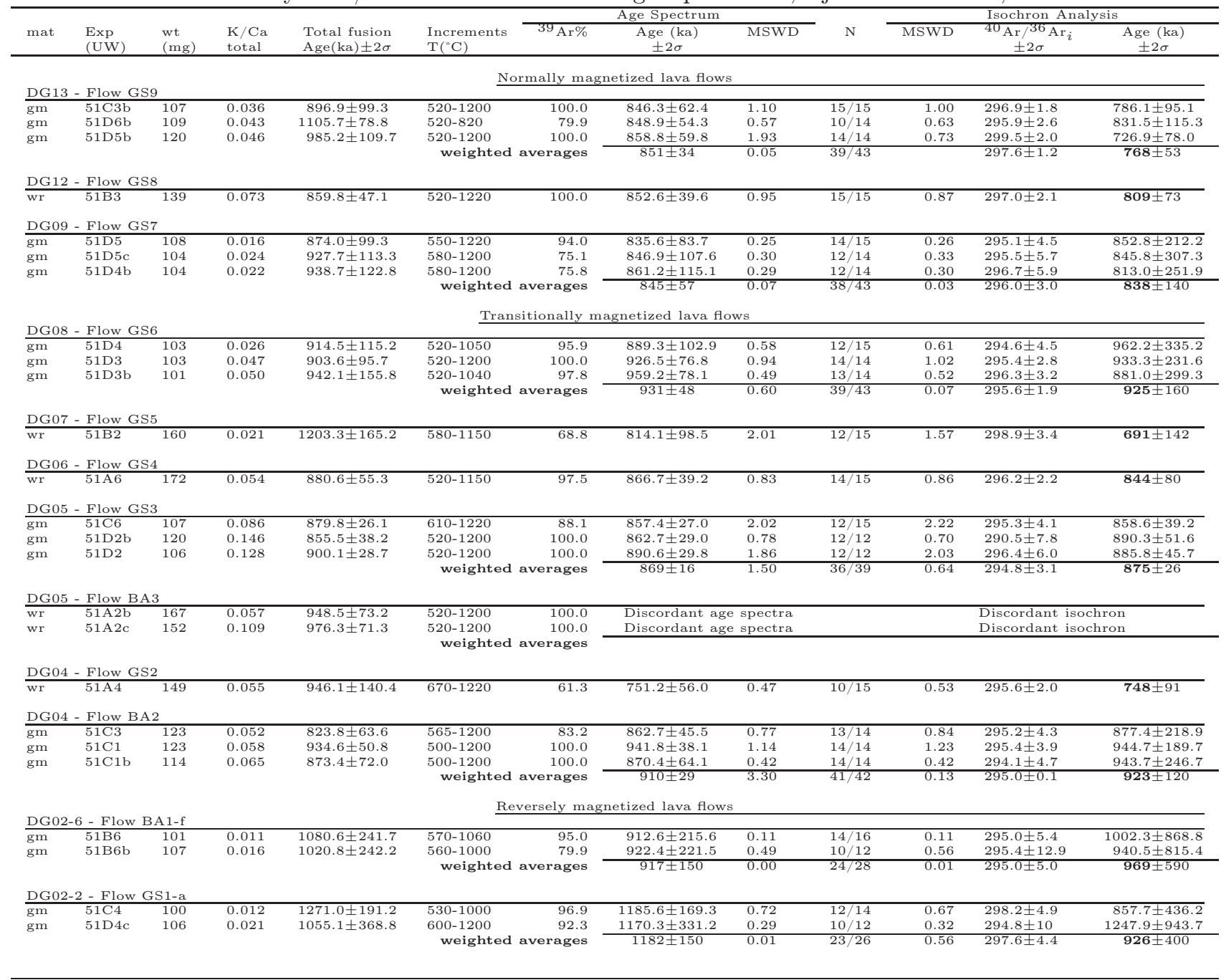

Analytical methods are summarized by Singer et al. [50]. Groundmass, gm; whole rock, wr. All ages calculated relative to $1.194 \pm 0.012$ Ma Alder Creek
rhyolite sanidine (ACs) [48] which is equivalent to an age of 28.02 Ma for the Fish Canyon sanidine (FCs) standard. The flows are listed in stratigraphic rhyolite sanidine (ACs) $[48]$ which is equivalent to an age of $28.02 \mathrm{Ma}$ for the Fish Canyon sanidine (FCs) standard. The flows are listed in stratigraphic
order with the youngest on top, oldest on the bottom. 